\author{
Universidade de São Paulo \\ Faculdade de Medicina de Ribeirão Preto \\ Departamento de Medicina Social
}

THAISE LUCENA SILVA

\title{
ALTERAÇÃO DO EQUIÍBRIO E MARCHA EM IDOSOS E OCORRÊNCIA DE QUEDAS
}

Ribeirão Preto 
THAISE LUCENA SILVA

\title{
ALTERAÇÃO DO EQUÍBRIO E MARCHA EM IDOSOS E OCORRÊNCIA DE QUEDAS
}

\author{
Dissertação apresentada ao Departamento de Medicina Social da Faculdade de \\ Medicina de Ribeirão Preto - FMRP - USP para obtenção do título de Mestre. \\ Área de Concentração: Saúde na Comunidade \\ Orientador: Prof. Dra. Amábile Rodrigues Xavier \\ Manço
}

Ribeirão Preto

2008 
Autorizo a reprodução e divulgação total ou parcial deste trabalho, por qualquer meio convencional ou eletrônico, para fins de estudo e pesquisa, desde que citada a fonte.

\section{FICHA CATALOGRÁFICA}

Silva, Thaise Lucena

eração do equilíbrio e marcha em idosos e ocorrência de uedas. 82 p.; il.; $30 \mathrm{~cm}$

Dissertação (Mestrado) apresentada à Faculdade de Medicina de Ribeirão Preto/USP - Área de concentração: Saúde na Comunidade.

Orientador: Amábile Rodrigues Xavier Manco.

1. Acidentes por quedas. 2. Idoso. 3. Equilíbrio musculoesquelético. 4. Marcha. 
FOLHA DE APROVAÇÃO

\section{THAISE LUCENA SILVA}

ALTERAÇÃO DO EQUILÍBRIO E MARCHA EM IDOSOS E OCORRÊNCIA DE QUEDAS

Dissertação apresentada à Faculdade de Medicina de Ribeirão Preto da Universidade de São Paulo para obtenção do Título de Mestre.

\section{Área de Concentração: Saúde da} Comunidade.

Aprovado em:

\section{Banca Examinadora}

Profa. Dra. Amábile RodriguesX. Manço

Instituição: FMRP-USP Assinatura:

Profa. Dra. Rosalina Ap. Partezani Rodrigues Instituição: EERP-USP Assinatura:

Prof. Dr. Amaury Lelis Dal-Fabbro Instituição: FMRP-USP Assinatura: 


\section{DEDICATÓRIA}

À Deus, pela oportunidade e por estar sempre presente em minha vida

Aos meus Pais que me apoiaram, e me ajudaram em tudo

Ao meu noivo Antonio, que me apoiou $e$ está presente em minha vida em mais uma conquista

A Professora Daneila Cristina Lojudice pelo incentivo à realização deste trabalho 


\section{AGRADECIMENTOS}

A Prof ${ }^{a}$. Dra Amábile Rodrigues Xavier Manço, pelas orientações e colaborações para o desenvolvimento do trabalho

Ao Prof Dr. Edson Zangiacomi Martinez, pela validosa colaboração na realização das análises estatísticas

A Prof ${ }^{a}$. Dra. Rosalina Ap. Partezani Rodrigues, Prof. Dr. Amaury Lelis Dal-

Fabbro, Prof. Dr.Julio Cesar Moriguti, pelas sugestões e ensinamentos recebido

Aos funcionários do Departamento de Medicina Social, em especial a Mônica, Carolina, Regina, Tânia e Solange, Obrigada pela paciência e pelo incentivo

Ao Lucas meu irmão e minha tia Jandira, por me incentivar a nunca desistir e me acompanhar nas vagens

Aos funcionários da Associação dos Aposentados e Pensionistas de Catanduva e Região (AAPCR), pela grande importância no agendamento dos idosos para a aplicação dos instrumentos de pesquisa

Aos IDOSOS pela grande importância na confecção desta pesquisa

À minha amiga Bernadete pelas palavras de conforto e incentivo

Á minha querida MÃE, Maria Helena, por todos os obstáculos vencidos, "Te Amo Mãe"

Ao meu “AMOR", pela compreensão, ajuda, e principalmente pela paciência. 
"O sábio, para ser feliz, olha abaixo de si e jamais acima,
a não ser para elevar sua alma até o infinito."

Allan Kardec 


\section{SUMÁRIO}

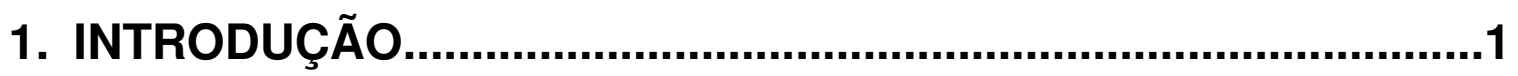

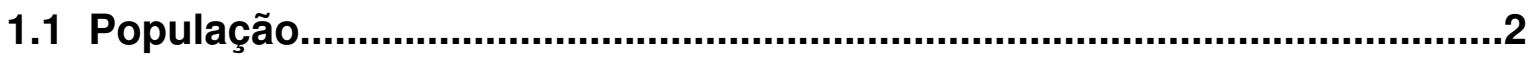

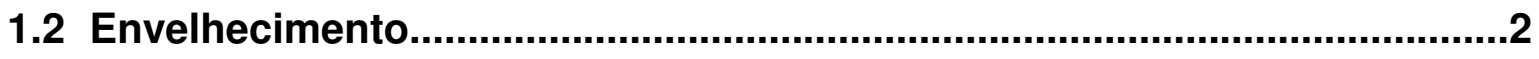

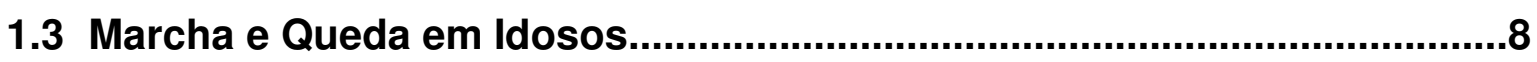

1.4 Alterações Cognitivas............................................................................11

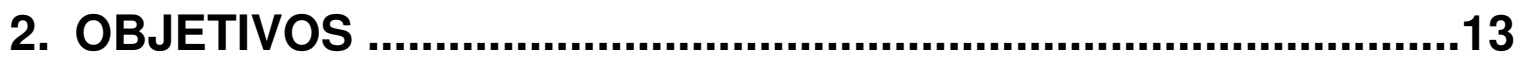

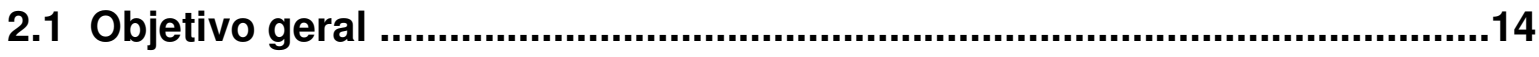

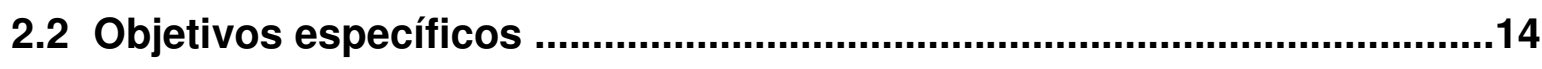

3. MATERIAIS E MÉTODOS...........................................................15

3.1 Delineamento do estudo......................................................................16

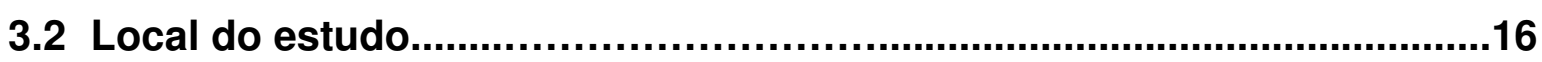

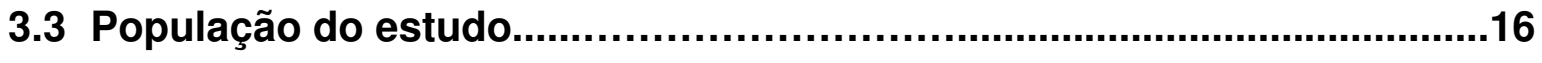

3.4 Critérios de Inclusão e Exclusão.......................................................17

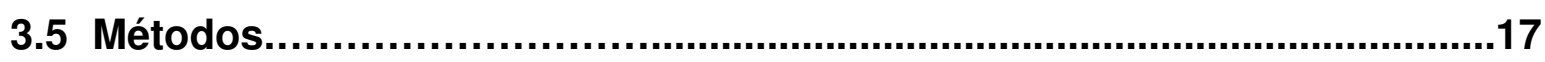

3.6 Análise dos Dados...........................................................................19

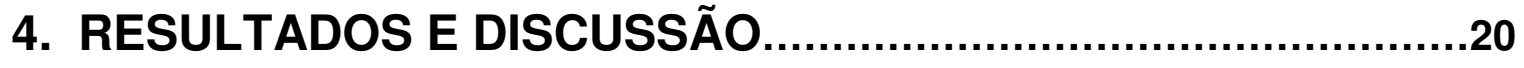

4.1 Características Sócio-demográficas..............................................21

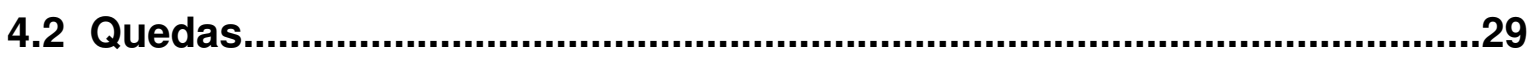

4.3 Condições extrínsecas..........................................................................30

4.4 Condições intrínsecas.............................................................................33

5. CONCLUSÕES

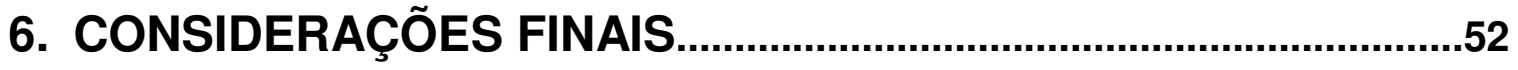

7. REFERÊNCIAS BIBLIOGRÁFICAS............................................54

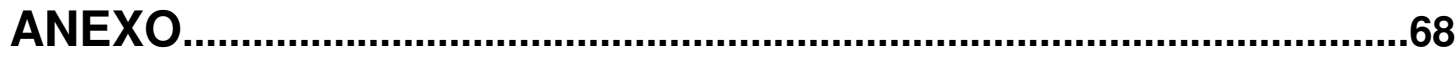

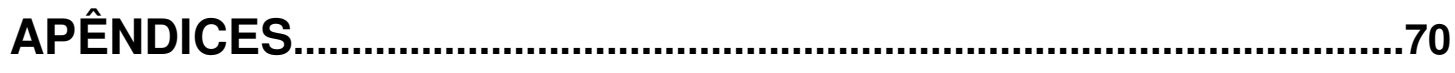




\section{LISTA DE TABELAS}

Tabela 1- Distribuição dos entrevistados segundo sexo,idade, 22 escolaridade,estado marital,residir só. Catanduva, 2008.

Tabela 2- Distribuição dos entrevistados segundo sexo, prescrição e uso de 24 medicamentos. Catanduva, $2008(\mathrm{n}=200)$.

Tabela 3- Distribuição dos entrevistados segundo sexo, uso de tabaco, 25 álcool e pratica de atividade física. Catanduva, 2008.

Tabela 4- Distribuição dos entrevistados segundo sexo e dados relacionados quanto ao uso de óculos e aparelho auditivo. Catanduva, 2008.

Tabela 5- Distribuição dos entrevistados segundo sexo e quedas. Catanduva, 2008.

Tabela 6- Distribuição dos entrevistados segundo sexo e condições extrínsecas da queda. Catanduva, $2008(\mathrm{n}=102)$.

Tabela 7- Distribuição dos entrevistados segundo sexo e o grupo de 33 medicamentos consumidos. Catanduva, 2008.

Tabela 8- Distribuição dos entrevistados segundo sexo e dados relatados sobre o que o participante atribuiu a queda. Catanduva, 2008 ( $\mathrm{n}=$ 102).

Tabela 9- Razão de incidência de quedas nos últimos 6 meses, ajustado por idade e uso de medicamentos, sexo e uso de medicamentos, sexo, idade e uso de medicamentos e por sexo e idade. Catanduva, 2008.

Tabela 10- Razão de incidência de quedas nos últimos 6 meses, ajustado por sexo, idade e uso de medicamentos. Catanduva, 2008.

Tabela 11- Razão de incidência de quedas nos últimos 6 meses, justado por sexo, idade e uso de medicamentos. Catanduva, 2008. 


\section{LISTA DE FIGURAS}

Figura 1- Distribuição da idade (em anos completos) dos idosos, segundo o sexo. Catanduva, 2008.

Figura 2- Distribuição dos valores obtidos pelos idosos na Escala de Avaliação do Desempenho Físico de Membros Inferiores, segundo o sexo. Catanduva, 2008.

Figura 3- Distribuição dos escores do MEEM dos idosos, segundo o sexo. Catanduva, 2008.

Figura 4- Distribuição de idade dos idosos e ocorrência de quedas nos últimos 6 meses. Catanduva, 2008.

38

Figura 5- Distribuição dos idosos segundo o MEEM e ocorrência de quedas 39 nos últimos 6 meses. Catanduva, 2008.

Figura 6- Distribuição dos escores do teste do equilíbrio e ocorrência de 40 quedas nos idosos nos últimos 6 meses. Catanduva, 2008. 


\section{RESUMO}

SILVA, T. L. Alteração do equilíbrio e marcha em idosos e ocorrência de quedas. 2008. 100p. Dissertação (Mestrado em Saúde na Comunidade) - Departamento de Medicina Social, Faculdade de Medicina de Ribeirão Preto, Universidade de São Paulo, Ribeirão Preto, 2008.

O envelhecimento populacional presente na maioria dos paises na atualidade inclusive no Brasil,tem sido associado ao aumento das quedas que estão se tornando cada vez mais freqüentes e sendo consideradas como um importante problema de saúde pública. O presente estudo realizado na Associação dos Aposentados de Catanduva e Região,teve como objetivo estudar as alterações de equilíbrio e marcha em idosos .e as associações com quedas. Foram pesquisados 200 idosos de ambos os sexos, com idade igual e superior a 60 anos. O método utilizado foi uma entrevista contendo perguntas abertas e fechadas, e para avaliação cognitiva foi aplicado o mini-exame do estado mental (MEEM) e a escala de avaliação de desempenho físico de membros inferiores (SPPB), com o intuito de avaliar o equilíbrio, marcha e a força destes membros. Para a análise dos dados foi utilizado o procedimento GENMOD do programa computacional SAS versão 9 , sendo considerado um nível de significância de 5\% ao testar hipóteses. e um intervalo de confiança de $95 \%$.Os resultados mostraram que $51 \%$ dos idosos sofreram quedas nos últimos 6 meses, os fatores de risco encontrados como significantes foram: idade de 70 a $74 \operatorname{anos}(\mathrm{p}=0,04)$ e de 75 a 79anos $(\mathrm{p}=<, 01)$, residir sozinho $(\mathrm{p}=<, 01)$, não possuir companheira $(\mathrm{p}=0,01)$, uso de medicamentos $(\mathrm{p}=0,05)$, número de medicamentos de 3 a $4(\mathrm{p}=0,04)$ e 5 ou mais $(\mathrm{p}=0,01)$,presença de fraqueza muscular $(\mathrm{p}=<, 01)$, largura dos passos pequenos $(\mathrm{p}=0,08)$, assimetria da marcha $\mathrm{p}=(0,09)$, presença de problemas nos pés ( $\mathrm{p}=0,07)$, uso de aparelho de audição $(\mathrm{p}=<, 01)$. Os resultados indicam a importância de uma equipe multidisciplinar, como medidas preventivas, visando diminuir as quedas possibilitando uma melhora das atividades básicas da vida diária (ABVDs), dessa forma tornando o idoso mais independente.

Palavras-chave: acidentes por quedas, idoso, equilíbrio musculoesquelético, marcha. 


\begin{abstract}
SILVA, T. L. Alteration of equilibrium and gait in the elderly and occurrence of falls. 2008. 100p. Dissertação (Mestrado em Saúde na Comunidade) - Departamento de Medicina Social, Faculdade de Medicina de Ribeirão Preto, Universidade de São Paulo, Ribeirão Preto, 2008

The current aging of the population in most countries, including Brazil, has been associated with an increase in falls, which are becoming more and more frequent and are considered to be an important public health problem. The objective of the present investigation, conducted at the Association of Retirees of Catanduva and Region, was to study the changes in equilibrium and gait among the elderly and their associations with falls. The study was conducted on 200 elderly subjects of both genders aged 60 years or more. The method used was an interview containing open and closed questions. The mental state mini-exam (MEEM) was applied for cognitive assessment and the scale for the assessment of lower limb physical performance (SPPB) was applied in order to evaluate equilibrium, gait and lower limb strength. Data were analyzed statistically using the GENMOD procedure of the SAS computational software, version 9 , at the $5 \%$ level of significance and with a $95 \%$ confidence interval. The results showed that $51 \%$ of the elderly subjects had suffered falls in the last 6 months, with the following risk factors being found to be significant: age of 70 to 74 years $(p=0.04)$ and of 75 to 79 years $(\mathrm{p}=<.01)$, living alone $(\mathrm{p}=<.01)$, having no female companion $(\mathrm{p}=0.01)$, use of medications $(\mathrm{p}=0.05)$, use of 3 to 4 medications $(\mathrm{p}=0.04)$ and of 5 or more $(\mathrm{p}=0.01)$, presence of muscle weakness $(\mathrm{p}=<.01)$, small step width $(\mathrm{p}=0.08)$, gait asymmetry $\mathrm{p}=(0.09)$, presence of foot problems $(\mathrm{p}=0.07)$, and use of a hearing aid $(\mathrm{p}=<.01)$. The results indicate the importance of a multidisciplinary team proposing preventive measures in order to reduce the falls and to permit an improvement of basic daily activities (ABVDs), thus turning the elderly more independent.
\end{abstract}

Key-words: accidents due to falls, elderly subjects, musculoskeletal equilibrium, gait. 


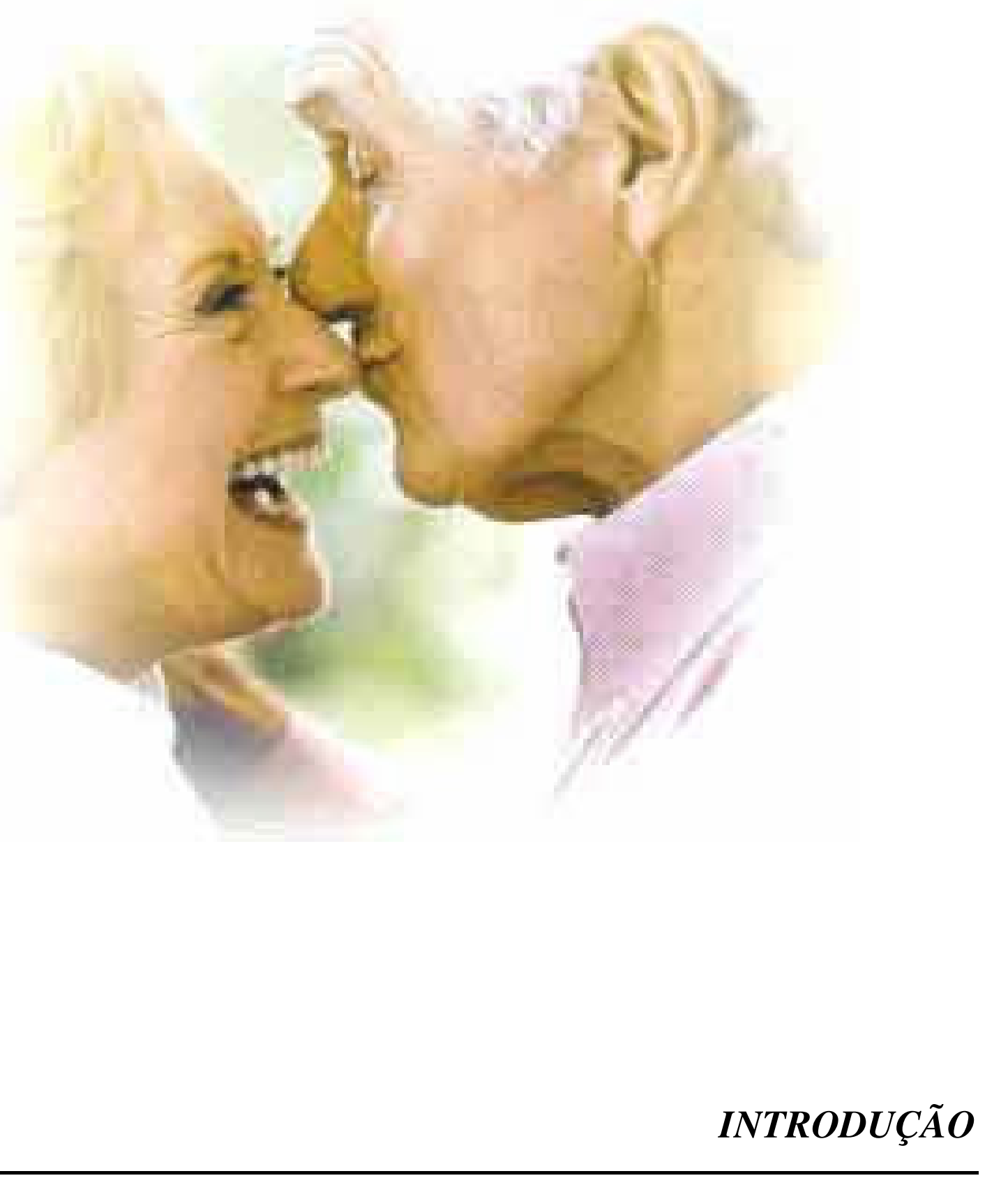




\section{INTRODUÇÃO}

\subsection{População}

A população idosa vem apresentando crescimento significativo nas últimas décadas devido a um progressivo declínio das taxas de mortalidade, declínio este resultante de alterações no perfil da morbidade conseqüente às mudanças das condições gerais de vida e de trabalho e ao avanço do conhecimento, predominantemente na área da saúde. Assinala-se que paralelamente a este declínio, o declínio das taxas de fecundidade, presente no Brasil a partir da década de sessenta, tem um grande peso no surgimento do envelhecimento populacional fato este sem precedentes na história do país .

Estima-se que no período entre 2000 e 2025, os idosos representarão 13,8\% da população total, e o país terá aproximadamente 34 milhões de pessoas acima de 60 anos (GOULART et al., 2003). A população de idosos no ano de 2000, representa um contingente de quase 15 milhões de pessoas com 60 anos ou mais de idade (8,6\% da população brasileira). As mulheres são maioria, somando 8,9 milhões correspondendo a 62,4\% dos idosos, são responsáveis pelos domicílios e têm, em média, 69 anos de idade e 3,4 anos de estudo. Com um rendimento médio de $\mathrm{R} \$ 657,00$, o idoso ocupa, cada vez mais, um papel de destaque na sociedade brasileira. No município de Catanduva/SP, a população estimada no ano de 2006 é de 116,984 habitantes, e no ano de 2001, a população de 60-64 anos era de 3,892 habitantes,de 65 a 69 anos correspondia a 3,309, de 70 a 74 anos era de 2,695, de 75 a 79 anos era composta por 1,701 , e de 80 anos ou mais era representada por 1,493, totalizando assim uma população idosa de 13,090 pessoas (IBGE, 2008).

\subsection{Envelhecimento}

Para Lafer et al. (2000), o envelhecimento populacional passou a ser uma realidade, decorrente do aparecimento de uma série de fenômenos conjugados, entre os quais, controle de doenças transmissíveis e doenças crônicas,maior disponibilidade de saneamento básico e uma melhora da qualidade de vida. 
Para o individuo ser considerado como idoso, vários fatores influenciam, assim como os aspectos políticos, ideológicos, sociais e culturais (VERAS, 2003). Considera-se como envelhecimento normal as alterações orgânicas, funcionais e psicológicas próprias que ocorrem em consequiência desse processo; senilidade ou envelhecimento patológico, são as modificações determinadas pelas afecções que frequentemente afetam os idosos que geralmente tiveram inicio em outras fases da vida e, ou deixaram seqüelas ou ainda estão presentes (Freitas et al., 2002; GEIB et al., 2003). O envelhecimento pode ser definido como, fenômeno do processo de vida que assim como na infância, adolescência e maturidade, é marcado por mudanças bio-psico-sociais específicas, associadas à passagem do tempo.

Papaléo Netto (2002), conceitua o envelhecimento como a incapacidade de manter o equilíbrio homeostático sob condições de descarga funcional, acarretando maior vulnerabilidade e processos patológicos, que podem levar o idoso a óbito.

Segundo Pereira et al. (2006), o processo de envelhecimento populacional, que nos países desenvolvidos ocorreu de forma gradual, acompanhado de melhorias na cobertura do sistema de saúde, nas condições de habitação, saneamento básico, trabalho e alimentação, no Brasil ocorreu rapidamente num contexto de desigualdades sociais, economia frágil, crescentes níveis de pobreza, com precário acesso aos serviços de saúde e reduzidos recursos financeiros, sem as modificações estruturais que respondam às demandas do novo grupo etário emergente.

Para Oliveira, Goretti e Pereira (2006), o envelhecimento, afeta desfavoravelmente o equilíbrio, produzindo mudanças em todos os níveis do controle postural, propiciando desordens nas três funções principais: os receptores sensoriais, o processamento cognitivo central e a execução da resposta motora. Estas desordens são decorrentes de múltiplas doenças crônicas, irreversíveis, ocasionando incapacidades e problemas associados. As alterações na mobilidade em idosos e portadores de demências estão associadas a quedas, fraturas e institucionalização. Funções locomotoras, sensoriais e cognitivas, estão intrinsecamente envolvidas na mobilidade, a qual está relacionada aos cuidados pessoais, interação social e atividades cognitivas, sugerindo que a avaliação cognitiva deve ser sempre acompanhada de uma avaliação funcional e vice-versa.

Com o passar dos anos, o organismo humano passa por um processo natural de envelhecimento, gerando modificações funcionais e estruturais no organismo, diminuindo a 
vitalidade e favorecendo o aparecimento de doenças. O envelhecimento compromete a habilidade do sistema nervoso central em realizar o processamento dos sinais vestibulares, visuais e proprioceptivos responsáveis pela manutenção do equilíbrio corporal e da locomoção, bem como diminui a capacidade de modificações dos reflexos adaptativos, e dos sistemas envolvidos (RUWER; ROSSI; SIMON, 2005).

Dentre esses sistemas os mais prejudicados são os sistemas músculo-esquelético, neuro-muscular e somatossensorial. No sistema músculo-esquelético ocorre à perda da força muscular e flexibilidade, que favorecem a rotação interna de ombros, cifose dorsal, retificação da lordose lombar, flexão de quadris e joelhos, com deslocamento posterior da articulação coxofemoral e inclinação do tronco para frente, tornando os desequilíbrios mais frequientes (GUCCIONE, 2002; BRANDT; RICIERI; GRIESBACH, 2004). Observa-se, também, a diminuição da amplitude de movimento, o que pode implicar em retrações nos componentes articulares, degenerações das cartilagens, com conseqüentes distúrbios intra-articulares e aumento de tensão nos ligamentos (HENRIQUES; PEREIRA; SILVA, 2004).

As alterações neuro-musculares prejudicam a coordenação dos músculos na realização das atividades, por degeneração das vias nigro-estriadas, que diminuem o desempenho motor, dificultam respostas sinérgicas, causando tremor de membros na execução do movimento. Ocorre também uma redução no controle do movimento voluntário e no tempo de reação desse movimento, por perdas de neurônios e outras substâncias do sistema nervoso central. Essas alterações tornam a marcha do idoso arrastada, com oscilações posturais, favorecendo os desequilíbrios (GUCCIONE, 2002).

O sistema músculo-esquelético é composto por dois tipos de músculos: dinâmico ou fásico e estáticos ou tônicos sendo que estes últimos representam 2/3 da nossa musculatura, são organizados em forma de cadeias musculares, onde cada músculo ou grupo muscular constitui um elo muscular. Isto determina que um estiramento local é compensado por um encurtamento em um ponto qualquer da cadeia muscular. Duas cadeias destacam-se como função estática: a cadeia anterior e a posterior. Quando a cadeia posterior está encurtada, a cadeia é projetada para frente, a região torácica aumenta sua curvatura cifótica e os ombros encontram-se, rodados internamente, com uma diminuição da lordose lombar, um aumento do ângulo de flexão do joelho, deslocamento da articulação coxofemural para trás e uma 
inclinação do tronco para frente, podendo ocasionar desequilíbrios posturais (BRANDT; RICIERI; GRIESBACH, 2004).

É justamente o desequilíbrio postural o coadjuvante das condições geradoras de incapacidades que contribuem para a queda da qualidade de vida na população idosa (HENRIQUES; PEREIRA; SILVA, 2004). Estudos revelam que 80\% dos casos não podem ser atribuídos a uma causa específica, mas sim a um comprometimento do sistema de equilíbrio como um todo. Em mais da metade dos casos o desequilíbrio tem origem entre 65 e 75 anos e cerca de $30 \%$ dos idosos apresentam as manifestações clínicas nesta faixa etária (MITSUCHI et al., 2004).

Estima-se que a prevalência de alterações do controle postural na população acima dos 65 anos chegue a 85\%, estando associada a várias etiologias, e podendo se manifestar como desequilíbrio, desvio de marcha, instabilidade, náuseas e quedas freqüentes (PERREIRA, 1995).

O sistema sensorial necessita de recursos somatossensoriais, vestibulares e visuais para executar ajustes aos movimentos, responsáveis pela a coordenação dos olhos, cabeça, pescoço e informação da localização dos objetos circundantes na orientação da velocidade do movimento (RIBEIRO; PEREIRA, 2004, ROSA, 2004). No idoso percebe-se a diminuição da eficácia desse sistema, com atrasos nas respostas aos estímulos oferecidos, dificultando a manutenção do equilíbrio em bípede ou na marcha, além da percepção, com consequientes quedas (RIBEIRO; PEREIRA, 2004, BARAÚNA, 2004, HATZITAKI; AMIRIDS; ARABATZI, 2005).

Quanto aos mecanismos que envolvem o equilíbrio, o antecipatório, ou seja, o mecanismo de resposta rápida para controle postural, perante as alterações externas geradas no corpo, está lentificado em aproximadamente $50 \%$ durante a execução dos movimentos voluntários dos idosos. Quando o controle é necessário em uma superfície, o idoso usa estratégias da região proximal para distal para adaptar-se, enquanto o adulto usa a distal para proximal. No mecanismo compensatório ocorre uma ativação muscular não usual - o idoso aumenta a ativação dos músculos extensores do pescoço, os quais são considerados necessários para compensar movimentos do tronco e estabilizar a cabeça e a orientação visual. Outra forma de compensar a instabilidade é a co-ativação dos músculos agonista e antagonista 
diminuindo o grau de liberdade e a quantidade de movimento para manter o equilíbrio (HATZITAKI; AMIRIDS; ARABATZI, 2005).

Junior e Heckmann (2002), definem o equilíbrio postural como o processo pelo qual o sistema nervoso central gera os padrões de atividade muscular necessários para regular a relação entre o centro de massa e a base de suporte. Na verdade, trata-se de uma atividade que requer um processo complexo envolvendo esforços coordenados de mecanismos aferentes ou sistemas sensoriais (visual, vestibular e proprioceptivo) e mecanismos eferentes ou sistemas motores (flexibilidade articular e força muscular dos membros superiores e inferiores). Tanto as respostas aferentes como as eferentes são devidamente organizadas por meio de uma gama de mecanismos centrais que possuem a função de receber e organizar as informações sensoriais e programar as respostas motoras apropriadas.

O sistema vestibular é uma das ferramentas mais importantes do sistema nervoso no controle postural, pois funciona ao mesmo tempo como sistema sensorial e motor. Ele fornece ao sistema nervoso central (SNC) informações sobre a posição e o movimento da cabeça e a direção da gravidade. O SNC usa essas informações, combinadas com as fornecidas por outros sistemas sensoriais, para construir uma imagem de posição e movimento do corpo todo e do ambiente que o cerca (ROSA, 2004) .

Para Ganança et al. (2006), a tontura é a sensação de perturbação do equilíbrio corporal. Pode ser definida como uma percepção errônea, uma ilusão ou alucinação de movimento, uma sensação de desorientação espacial do tipo rotatório (vertigem) ou não rotatório (instabilidade, desequilíbrio, flutuação, oscilação, oscilopsia). Não é rara a ocorrência de tonturas de diversos tipos (rotatórios e não-rotatórios) num mesmo indivíduo. Ambos os tipos podem ser ou não por distúrbio vestibular, que pode ser comprovado por meio de exame otoneurológico. As tonturas são decorrentes de desordens funcionais primárias ou secundárias do sistema vestibular em aproximadamente $85 \%$ dos casos e os distúrbios do equilíbrio em idosos têm como principal complicação a queda.

Vale ressaltar que o sistema vestibular junto às aferências proprioceptivas, visuais e auditivas adaptam ou memorizam movimentos realizados pelo corpo humano e a execução repetida de exercícios faz com que as informações sejam armazenadas, criando ajustes necessários para a manutenção de equilíbrio ( RIBEIRO; PEREIRA, 2004). 
O sistema proprioceptivo contribui para o equilíbrio ao fornecer informação acerca da localização relativa das partes corporais. Ele fornece informações sobre a posição e o movimento do corpo em relação à superfície de apoio e, sobre a posição e o movimento dos segmentos do corpo em relação uns aos outros e a superfície de apoio, descrevendo o estiramento muscular e a posição articular do tornozelo ou de articulações mais proximais. $\mathrm{O}$ sistema proprioceptivo é particularmente sensível aos movimentos rápidos, como os produzidos por perturbações repentinas nas posições articulares. As informações provenientes desse sistema ajudam a coordenar os movimentos dos olhos, da cabeça e do pescoço, com a finalidade de estabilizar o sistema visual, a manter as posturas e os padrões coordenados do movimento ( ROSA, 2004).

Rosa (2004), acrescenta que o sistema visual também fornece informações sobre a direção vertical, a posição e o movimento da cabeça em relação aos objetos circundantes e orienta a cabeça a manter uma posição correta além de informar acerca do movimento dos objetos circundantes, oferecendo assim, orientação da velocidade do movimento.

Russo (1998), ressalta que o envelhecimento compromete a habilidade do sistema nervoso central em realizar o processamento dos sinais vestibulares, visuais e proprioceptivos responsáveis pela manutenção do equilíbrio corporal, bem como diminui a capacidade de modificações dos reflexos adaptativos. O mesmo autor afirma que esses processos degenerativos são responsáveis pela ocorrência de vertigem e/ou tontura (presbivertigem) e de desequilíbrio (presbiataxia) na população idosa.

As alterações posturais também devem ser valorizadas pois estão relacionadas com o envelhecimento articular gerando limitações na amplitude de movimento devido a retrações na cápsula articular, a tensão aumentada nos ligamentos e a degeneração da cartilagem articular. As doenças articulares afetam principalmente a coluna vertebral e os membros inferiores, causando dor e instabilidade, podendo levar a fraturas e necessitando, muitas vezes, da utilização de próteses e órteses.

As alterações cardiovasculares, como arritmias e infarto agudo do miocárdio, alterações neurológicas como crises convulsivas, alterações psicológicas e psiquiátricas, como ansiedade e depressão estão associadas à ocorrência de quedas em idosos (GUCCIONE, 2002, HENRIQUES; PEREIRA; SILVA, 2004). 


\subsection{Marcha e Queda em Idosos}

A marcha é definida como uma forma ou estilo de caminhar, sendo dividida em duas fases, a fase de apoio e de balanço. A fase de apoio constitui $60 \%$ do ciclo e se subdivide em quatro fases, denominadas de: resposta de carga, apoio intermediário, apoio terminal e prébalanço, e ocorre quando uma perna suporta todo o peso e se mantém em contato com a superfície. Essa fase permite que a perna de apoio sustente o peso do corpo que, então, pode avançar. No período de apoio há momentos de apoio unipedal e bipodal, dedos fora é o termo para a transição entre o apoio e balanço. A fase de balanço ocorre quando a perna que não faz apoio avança para o próximo passo, e esta é subdividida em três etapas: balanço inicial, intermediário e terminal (FREITAS, 2006).

A marcha se dá por meio de uma série de fases alternadas de apoio e balanço, com os braços se movimentando no sentido inverso ao das pernas do mesmo lado para manter o equilíbrio.

Durante a fase de apoio verificam-se três atividades principais, $\mathrm{O}$ contato inicial (apoio de calcanhar) representa o início e a fase de apoio. $\mathrm{O}$ apoio intermediário (apoio unipedal) ocorre na metade dessa fase. $\mathrm{O}$ apoio terminal (calcanhar fora) representa o ponto no qual o calcanhar de referência sai do solo e avança o corpo para frente. A fase de balanço, em sua etapa inicial (aceleração) ocorre quando o dedo da extremidade deixa o solo e continua até a etapa intermediária ou o ponto no qual a extremidade em balanço está diretamente sobre o corpo. A partir daí, no balanço terminal (desaceleração), a perna se prepara para o contato inicial com o solo ou está pronta para o suporte de peso (contato inicial), quando a fase de apoio se reinicia (ABREU, 2003).

A queda é definida como um evento não-intencional que tem como resultado a mudança de posição do indivíduo para um nível inferior em relação a sua posição inicial, sem que tenha havido um fator intrínseco determinante, como um acidente vascular cerebral ou síncope, ou um acidente inevitável (BARAÚNA, 2004).

As quedas são as conseqüências mais perigosas do desequilíbrio e da dificuldade de locomoção, sendo seguidas por fraturas, deixando os idosos acamados por dias ou meses e sendo responsáveis por $70 \%$ das mortes acidentais em pessoas com mais de 75 anos (FULLER, 2000, WEINCHUCH; KORPER; HALDLEY, 1997, BITTAR et al., 2003). 
De fato há duas condições que devem ser satisfeitas para que haja a ocorrência da queda: a primeira, é a existência de uma perturbação do equilíbrio e a segunda, que haja uma falência do sistema de controle postural em compensar essa perturbação. Há dois tipos classificatórios de perturbação: a interna e a externa. A interna é considerada fisiológica, ela acontece quando se interrompe momentaneamente a operação do sistema de controle postural por interferência na perfusão dos centros posturais localizados no cérebro ou tronco cerebral como, por exemplo, nos ataques isquêmicos transitórios, hipotensão postural, arritmias cardíacas, oclusão das artérias vertebrais durante a movimentação cervical. Já a perturbação externa pode ainda ser subdividida em mecânica e informacional. Na mecânica, as forças que interagem com o corpo humano tentam de alguma forma desestabilizar o centro de massa ou a própria base de suporte, como acontece nos casos de um empurrão, colisão, escorregão ou tropeço. Por último, na perturbação informacional o que encontra-se alterado é a natureza da informação de orientação do ambiente, isto é, a falta de luminosidade local ou ilusões de automovimento que são as responsáveis pela ocorrência de queda. (JÚNIOR; HECKMANN, 2002).

Existem fatores que determinam se uma lesão vai ocorrer. São eles: área de impacto durante a queda (que se for pequena levará a uma maior probabilidade de fratura), ausência de reflexos de proteção, ausência de acolchoamento natural do corpo, resistência e rigidez da superfície sobre a qual se dá a queda, densidade óssea, índice de massa corpórea menor (pessoas magras), uso de restrições, maior estrutura, idade e sexo feminino (FILHO; NETTO, 2005).

O medo de cair também tem sido relacionado com quedas que resultaram em fraturas e com quedas cuja circunstância não foi devida a um evento puramente acidental, como tropeções ou escorregões e sim a um distúrbio de equilíbrio. Além das correlações já apontadas, o medo de cair está também relacionado à diminuição da mobilidade, a uma baixa satisfação com a vida e a humor deprimido, causado por uma percepção realista da perda de função e conseqüente vulnerabilidade a novas quedas (PERRACINI, 2000).

A avaliação funcional do equilíbrio corporal e da mobilidade em idosos é um processo que requer a avaliação de vários sistemas envolvidos no mecanismo do controle postural. Várias escalas e testes funcionais têm sido desenvolvidos com o propósito de identificar comprometimento do equilíbrio e marcha em idosos (PÉRENNOU, 2005, RUWER, 2005). 
Para Pérennou (2005), diagnosticar as alterações do equilíbrio e marcha é possível, por meio da avaliação com testes baseados em medidas métricas, da posturografia, da percepção da verticalização e escalas, como a escala de avaliação do equilíbrio e da marcha de Tinetti. Este avalia o equilíbrio em diferentes situações: sentado, levantando da cadeira, ficando em pé com olhos abertos e fechados, e a posição de Romberg em apoio unipodal e realizando um giro de $360^{\circ}$. Essas técnicas são complementares e sua associação é recomendada em um contexto clínico, permitindo aplicabilidade e confiabilidade da avaliação.

Em estudo realizado por Paula (2007), no município de Campinas, no ambulatório de Geriatria do Hospital das Clínicas da Universidade Estadual de Campinas (UNICAMP) foram avaliados 122 idosos de 60 anos ou mais. Foram analisados a mobilidade e flexibilidade (SPPB), cognição (MEEM), bem-estar subjetivo, independência funcional (MIF), dados sócio-demográficos, de saúde física, antropométricos. O estudo concluiu que os testes funcionais estiveram associados entre si e aos demais indicadores de saúde estudados, sendo úteis para detectar alterações de saúde que podem demandar intervenção. A SPPB e o MEEM, além de se correlacionarem com a MIF, detectaram alterações não percebidas por ela no grupo mais idoso. Este grupo, mesmo com menor desempenho em testes funcionais, apresentou maior grau de bem-estar subjetivo.

Para Steadman et al. (2003), o equilíbrio é necessário para mobilidade, funcionalidade e confiança do idoso, mas o ato de deambular é particularmente importante, para a percepção e habilidade, diminuindo a dependência e número de quedas.

De acordo com Oliveira, Goretti e Pereira (2006), quando os idosos apresentam distúrbios de marcha e equilíbrio, eles estão expostos a situações de risco, como obstáculos em seu ambiente doméstico, tornando-se mais sujeitos as quedas. $\mathrm{O}$ fato de o idoso ter uma diminuição da capacidade de perceber onde está, onde pisa, faz com que o mesmo não esteja atento aos obstáculos ambientais, dentre estes a presença de degraus, o que o coloca em situações de risco.

Um estudo realizado por Lojudice, (2005) no município de Catanduva, que buscou avaliar a ocorrência de quedas e seus fatores determinantes na velhice, em uma população de 105 idosos residentes em instituições asilares, encontrou que 40\% sofreram quedas e desses, $61,9 \%$ se apresentaram com pontuação inferior a 19 na escala de avaliação do equilíbrio e marcha de Tinetti, ou seja, com dificuldade no equilíbrio e marcha. 
Faria et al (2003), relatam que, com a idade ocorrem alterações na marcha devido a mudanças, tais como encurtamento e diminuição da altura do passo, alargamento da base de suporte, diminuição da velocidade da marcha e da extensão do joelho e quadril, além do aumento da fase de apoio e do tempo de duplo suporte. Em decorrência disso, os idosos desenvolvem uma marcha com maior gasto energético, o que pode desencadear um declínio das atividades desempenhadas e conseqüentemente, uma diminuição da força muscular, contribuindo para a deterioração da função motora.

Dentre as condições geradoras de incapacidades que podem afetar a população idosa destaca-se a instabilidade postural que ocorre com freqüência entre os idosos, alterando o equilíbrio e dificultando a locomoção, levando a quedas e diminuindo a qualidade de vida (CARLOS et al., 2005).

\subsection{Alterações cognitivas}

Alterações do estado mental, agudas ou crônicas, são casos comuns na prática clínica, devendo tornar-se ainda mais freqüentes à medida que aumenta a expectativa de vida da população brasileira. O pronto reconhecimento de tais alterações é fundamental para dar prosseguimento à investigação diagnóstica, embora seja muitas vezes fonte de dúvidas para o clínico. O diagnóstico de condições como delirium ou demência deve ser realizado através de avaliação objetiva do estado mental (CARAMELLI; NITRINI,2000).

No Brasil, Bertolucci et al. foram os primeiros a investigar o valor diagnóstico deste teste em uma população geral, observando o grande efeito da escolaridade sobre o desempenho. Com base nos dados de estudo epidemiológico recente, realizado, na identificação de pacientes com suspeita de demência, tem-se empregado as notas de corte de 18 (analfabetos), 21 (1-3 anos de escolaridade), 24 (4-7 anos) e 26 (> 7 anos) (CARAMELLI, NITRINI, 2000).

Em estudo desenvolvido por Caramelli, Nitrini (2000), utilizando o Mini-Exame do Estado Mental (MEEM) aplicado em 530 indivíduos classificados segundo idades de 45- 64 anos e escolaridade, constatou-se que, para essa amostra, a idade não interferiu nos escores alcançados. Entretanto, ao comparar quatro níveis de escolaridade (analfabetos, baixa, média e alta) obteve-se diferença estatística significante $(\mathrm{p}<0,0001)$ entre escores, exceto para os 
indivíduos de baixa e média escolaridade quando comparados entre si. Foram estipulados valores de corte para cada grupo, tomando-se como referência o percentil 5 por cento da porção inferior da curva de distribuição dos valores dos escores. Estes foram: 13 para analfabetos, 18 para baixa e média e 26 para alta escolaridade. Comparando-se estes resultados aos obtidos com o MEEM, em 94 indivíduos com déficits cognitivos comprovados, utilizando os níveis de corte determinados encontrou-se: sensibilidade de $82,4 \%$ para analfabetos, 75,6 \% para baixa e média e $80 \%$ para alta escolaridade; e especificidade de 97,5\% para analfabetos, 96,6 \% para baixa e média e 95,6\% para alta escolaridade (BERTOLUCCI et al., 1994).

Segundo Bertolucci et al. (1994), devem ser utilizados níveis de corte diferenciados para cada grau de escolaridade para que erros diagnósticos possam ser minimizados.

O tratamento médico pode utilizar-se de drogas antiinflamatórias e aconselha-se a fisioterapia para realizar o treinamento específico para promover uma boa qualidade de vida para o envelhecimento humano (ISHIZUKA et al., 2004).

O fisioterapeuta deve avaliar e diagnosticar as mudanças que podem ser esperadas com o envelhecimento e que alteram a postura ereta. A fisioterapia contribui na fase preventiva, na fase de atuação imediata, nas orientações das atividades de vida diária e nas orientações aos familiares (GUCCIONE, 2002).

Portanto, pode-se afirmar que as manifestações dos distúrbios do equilíbrio corporal têm grande impacto na vida dos idosos, podendo levá-los à redução de sua autonomia social, uma vez que acabam reduzindo suas atividades de vida diária, pela predisposição a quedas e fraturas, trazendo sofrimento, imobilidade corporal, medo de cair novamente e altos custos com o tratamento de saúde.

Tendo em vista que a população brasileira está envelhecendo, que as alterações relatadas podem acompanhar o processo de envelhecimento e trazer prejuízos para o envelhecimento saudável, que as quedas podem ser causas importantes de adoecimento, incapacidades e de morte, torna-se importante pesquisar as alterações do equilíbrio e marcha em idosos. Assim no presente trabalho procurou-se estudar estas alterações entre idosos no município de Catanduva, São Paulo, que freqüentam a associação dos aposentados, que apesar de terem acesso ao tratamento fisioterapêutico e muitos serem independentes, apresentam grandes dificuldades ao deambular e ao realizar movimentos rápidos. 


\section{OBJETIVOS}

$=$ 


\section{OBJETIVOS}

\subsection{Objetivo Geral:}

Identificar as alterações de equilíbrio e marcha em idosos e as associações com quedas.

\subsection{Objetivos Específicos:}

- Identificar idosos com dificuldades no equilíbrio e marcha.

- Verificar se há associação entre dificuldade do equilíbrio e marcha e a ocorrência de quedas.

- Verificar algumas variáveis relacionadas à dificuldade de equilíbrio, marcha e quedas.

- Correlacionar o evento queda com os fatores extrínsecos. 
MATERIAIS E MÉTODOS

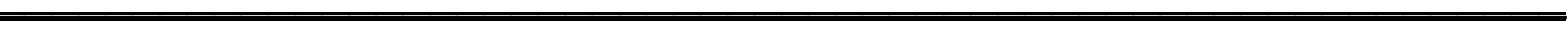




\section{MATERIAIS E MÉTODOS}

\subsection{Delineamento do estudo}

Trata-se de um estudo descritivo transversal

\subsection{Local do estudo}

O presente estudo foi realizado no município de Catanduva/SP na Associação dos Aposentados e Pensionistas de Catanduva e Região. O interesse em realizar a pesquisa na Associação dos Aposentados, deu-se pelo fato de haver um grande número de idosos que freqüentam diariamente o local. A Associação dos Aposentados apresenta 5.000 associados dentre os quais 3.950 pessoas com 60 anos ou mais, atende em média 220 pessoas por dia, sendo mantida pelos próprios associados, os quais contribuem mensalmente com $1 \%$ do salário. Oferece atendimento, na área da saúde (Médico, Fisioterapêutico, Psicológico, Odontológico, Protético, Farmacêutico), Jurídico e de lazer (locação de fitas de vídeo e DVD, rancho, colônia de férias, e departamento turístico e lava- jato).

\subsection{População do estudo}

A população do estudo foi constituída por idosos de ambos os sexos, com ou sem alterações de equilíbrio e marcha, filiados à Associação dos Aposentados e Pensionistas de Catanduva e Região. São indivíduos de classe média e baixa, de 60 a 90 anos, residentes no município de Catanduva, os quais dependem de ônibus ou ambulância para chegarem até o local.

A seleção dos idosos, foi realizada por sorteio, utilizando dados. Alguns idosos nunca tinham participado de pesquisas, o que pode, em parte, justificar a resistência por parte dos mesmos. 
A avaliação dos idosos foram aplicados na sala de fisioterapia da Associação dos Aposentados, onde havia total privacidade dos entrevistados. Antes de iniciar a aplicação dos mesmos, o projeto de pesquisa foi submetido a apreciação do Comitê de Ética e Pesquisa (nº1/07) da Faculdade Medicina de Catanduva - FAMECA, elaborado um termo de consentimento que era assinado após os devidos esclarecimentos e os participantes podiam desistir ou se recusar de participar da pesquisa.

\subsection{Critérios de Inclusão e Exclusão}

Indivíduos devidamente cadastrados na Associação dos Aposentados, residentes no município de Catanduva/SP, com 60 anos ou mais.

\subsection{Métodos}

Inicialmente a pesquisadora realizou a coleta de dados, utilizando três Instrumentos: $1^{\circ}$-Questionário para a coleta de dados, composto por perguntas abertas e fechadas, contendo dados de identificação do entrevistado, como idade, sexo, estado civil, escolaridade e outras informações relacionadas a atividade física, estado de saúde, medicamentos usados, número de medicamentos, número e freqüência de oscilações, presença de fraqueza muscular, dificuldade na marcha (passo prolongado, altura e largura do passo, simetria) e o número de quedas (LOJUDICE, 2005; GURALNIK, 1994).

$2^{\circ}$-Escala de avaliação do desempenho físico de membros inferiores, utilizando a Short Physical Performance Battery (SPPB), validada por Guralnik et. al. (1994). Este instrumento avalia a função das extremidades inferiores, o equilíbrio, a marcha, a força e a resistência, através da observação direta do desempenho.

Essa escala foi validada por Guralnik (1994) e adaptada por Nakano (2007), em uma versão português para o Brasil, que apresenta três itens de avaliação para propensão a quedas em idosos, dispostos por fases, com a finalidade de conhecer o equilíbrio, velocidade e 
flexibilidade. A primeira fase refere-se ao Teste de Equilíbrio, a segunda ao teste de Velocidade de Marcha e a terceira ao Teste de Força dos Membros Inferiores.

No presente estudo, foram coletados os dados referentes às três fases, na segunda fase do SPPB, que avalia a velocidade da marcha do idoso, com pontuação entre 0 e 4 pontos, marcando-se com um cronômetro o tempo de marcha relacionado à ida, no primeiro momento, e o tempo de marcha, relacionado à volta, em um segundo momento. A seguir, escolhe-se o melhor tempo, ou seja, aquele que se refere a menor velocidade de marcha.

Quando o idoso pontua 0, isso significa que o mesmo foi incapaz de realizar o movimento; 1 ponto, atribui-se ao que atinge um tempo de marcha com velocidade superior a 8,70 segundos; 2 pontos, quando o tempo de marcha fica entre 6,21 e 8,70 segundos; a pontuação 3 significa que o tempo de marcha está entre 4,83 e 6,20 segundos; finalmente, a pontuação 4 significa que o idoso realizou o teste em um tempo inferior a 4,82 segundos.

Além das vantagens mencionadas, a SPPB oferece três testes importantes para avaliar a funcionalidade de MMII em um só instrumento, o que Guralnik et al. (2000) reconhecem aumentar a confiabilidade dos resultados. Guralnik et al. (1994) referem-se à padronização de testes de desempenho físico como complemento valioso e necessário na avaliação gerontológica.

$3^{\circ}$-Mini Exame do Estado Mental (MEEM) que segundo Folstein, Folstein, Mchugh, (1975) é provavelmente o instrumento mais utilizado mundialmente, possuindo versões em diversas línguas e paises. Ja foi validado para a população brasileira. Fornece informações sobre diferentes parâmetros cognitivos2-8, contendo questões agrupadas em sete categorias, cada uma delas planejada com o objetivo de avaliar "funções" cognitivas especificas como a orientação temporal (5 pontos), orientação espacial (5 pontos), registro de três palavras (3 pontos), atenção e calculo (5 pontos), recordação das três palavras (3 pontos), linguagem (8 pontos) e capacidade construtiva visual (1 ponto). O escore do MEEM pode variar de um mínimo de 0 pontos, o qual indica o maior grau de comprometimento cognitivo dos individuos, ate um total máximo de 30 pontos, o qual, por sua vez, corresponde a melhor capacidade cognitiva.

Brucki et al. (2003), descreveu adaptações para uso do MEEM no Brasil e propôs regras para uniformizar sua aplicação. Estabelecendo os pontos de corte de acordo com a escolaridade (Analfabetos: 20; Escolaridade 1-4: 25; 5-8: 26,5; 9-11: 28; >11: 29). 


\subsection{Análise dos dados}

Modelos lineares generalizados Nelder e Wedderburn (1972) para variável resposta com distribuição binária (quedas nos últimos 6 meses, presentes ou ausentes) e função de ligação logarítmica, como definidos por Skov et al (1998), foram utilizados para estimar razões de incidência (RI) de quedas. Estes modelos estimaram RI brutas e ajustadas pelo efeito de confundimento do sexo, idade e uso de medicamentos, com seus respectivos intervalos de confiança de $95 \%$. Para o ajuste destes modelos, foi utilizado o procedimento GENMOD do programa computacional SAS versão 9 , sendo considerado um nível de significância de $5 \%$ ao testar hipóteses. 
RESULTADOS E DISCUSSÃO 


\section{RESULTADOS E DISCUSSÃO}

\subsection{Características Sócio-demográficas}

Foram entrevistados 200 idosos, sócios da Associação dos Aposentados e Pensionistas de Catanduva/SP e Região, aos quais foram aplicados um questionário e uma escala de Avaliação de Força de Membros Inferiores (SPPB) e o Mini-Exame do Estado Mental (MEEM) para avaliação cognitiva.

Dos idosos entrevistados 92 eram do sexo masculino e 108 eram do sexo feminino, com média de idades de 69,9 homens e 70 anos para as mulheres, variando de 60 a 80 anos ou mais.

A coleta de dados transcorreu satisfatoriamente, devido à colaboração dos idosos. 
Tabela 1 - Distribuição dos idosos segundo sexo, idade, escolaridade, estado marital, e com quem mora. Catanduva, 2008.

\begin{tabular}{|c|c|c|c|c|c|}
\hline & \multirow[b]{2}{*}{ Total $(\%)$} & \multicolumn{4}{|c|}{ Sexo } \\
\hline & & Masculino & $(\%)$ & Feminino & $(\%)$ \\
\hline \multicolumn{6}{|l|}{ Idade (anos) } \\
\hline 60 a 64 & $50(25)$ & 22 & (24) & 28 & $(26)$ \\
\hline 65 a 69 & $52(26)$ & 23 & $(25)$ & 29 & $(27)$ \\
\hline 70 a 74 & $47(24)$ & 24 & (26) & 23 & $(21)$ \\
\hline 75 a 79 & $33(16)$ & 16 & (17) & 17 & $(16)$ \\
\hline$\geq 80$ & 18 (9) & 7 & (8) & 11 & $(10)$ \\
\hline \multicolumn{6}{|l|}{ Escolaridade } \\
\hline Analfabeto & $34(17)$ & 11 & (12) & 23 & $(21)$ \\
\hline Primário incompleto & $109(55)$ & 51 & (56) & 58 & $(54)$ \\
\hline Primário completo & $26(13)$ & 12 & (13) & 14 & (13) \\
\hline Ginásio incompleto & $7 \quad(3)$ & 5 & $(5)$ & 2 & (2) \\
\hline Ginásio completo & $1 \quad(<1)$ & 0 & - & 1 & $(<1)$ \\
\hline Colegial completo & 8 (4) & 4 & (4) & 4 & (4) \\
\hline Superior completo & $15 \quad(8)$ & 9 & (10) & 6 & (6) \\
\hline \multicolumn{6}{|l|}{ Estado Marital } \\
\hline Com companheiro(a) & $119(60)$ & 69 & (75) & 50 & $(46)$ \\
\hline Sem companheiro(a) & $81(40)$ & 23 & $(25)$ & 58 & $(54)$ \\
\hline \multicolumn{6}{|l|}{ Reside sozinho } \\
\hline Sim & $30(15)$ & 10 & (11) & 20 & (19) \\
\hline Não & $170(85)$ & 82 & (89) & 88 & (82) \\
\hline Total & $200(100)$ & 92 & (100) & 108 & (100) \\
\hline
\end{tabular}

Com relação à idade, houve um equilíbrio entre os idosos do sexo masculino e feminino, sendo 92 homens e 108 mulheres.

Notou-se uma maior porcentagem de mulheres analfabetas $(21 \%)$ em relação aos idosos do sexo masculino (12\%). 
Quanto ao estado marital, observou-se maior porcentagem de idosas sem companheiro, que residem sozinhas, achados estes que podem ser esperados tendo em vista que a mortalidade é sempre maior no sexo masculino o que leva a uma maior sobrevida feminina. É comum que as uniões entre os sexos ocorram, com maior freqüência, entre homens mais velhos e mulheres mais novas e que as mulheres que perderam seus companheiros por morte ou separação, tenham menor probabilidade de contrair novas uniões.

Um estudo realizado por Reis et al. (2007), composto por 120 idosos em tratamento fisioterapêutico no setor de Neurogeriatria da Clínica Escola de Fisioterapia (CEF), da Universidade Estadual do Sudoeste da Bahia (UESB) no período de agosto de 2005 a agosto de 2006, em idosos de ambos os sexos, com idade igual ou superior a 60 anos, sendo (56,7\%) do sexo feminino e $(43,3 \%)$ do sexo masculino.. Em relação ao estado civil, 56,67\%) eram casados; $12,50 \%$ solteiros; $21,67 \%$ viúvos; 4,16\% divorciados e 5\% não informaram.

Houve semelhança com os achados do estudo realizado por Signoretti (2007), no qual ficou evidenciado que o gênero feminino prevalece numericamente sobre o gênero masculino em todas as faixas etárias $(61 \%)$.

Um estudo realizado por Rocha et al. (2005), nos mostra, que no grupo de viúvas entrevistadas, havia 23 idosas, entre as quais mais de (50\%) eram viúvas e apenas uma tinha um novo companheiro. $\mathrm{O}$ fato de a maioria das viúvas permanecerem só, nos mostra que mais da metade das mulheres entre 65 e 70 anos não têm um novo companheiro, o que decorre não só do fato de o homem morrer mais cedo, casar com mulheres mais novas após a viuvez, mas também que a maioria das mulheres viúvas não recasar (IBGE, 2004). Ao envelhecer, muitas pessoas às vezes ficam sem parceiro, de modo particular para as mulheres, quer devido a sua maior expectativa de vida quer pela menor oportunidade de contrair segundas núpcias após a viuvez (CAPODIECI, 2000). 
Tabela 2 - Distribuição dos idosos segundo sexo, prescrição e uso de medicamentos. Catanduva, $2008(\mathrm{n}=200)$.

\begin{tabular}{|c|c|c|c|c|c|}
\hline & \multirow[b]{2}{*}{ Total $(\%)$} & \multicolumn{4}{|c|}{ Sexo } \\
\hline & & Masculino & $(\%)$ & Feminino & $(\%)$ \\
\hline \multicolumn{6}{|c|}{ Uso de Medicamentos } \\
\hline Sim & $160(80)$ & 65 & (71) & 95 & $(88)$ \\
\hline Não & $40(20)$ & 27 & (29) & 13 & (12) \\
\hline \multicolumn{6}{|c|}{ Origem da Receita } \\
\hline Médico & $160(80)$ & 66 & (72) & 95 & $(88)$ \\
\hline Sem Receita & $40(20)$ & 26 & $(28)$ & 13 & (12) \\
\hline \multicolumn{6}{|c|}{$\mathrm{N}^{\mathrm{o}}$ de Medicamentos } \\
\hline 0 & $40(20)$ & 26 & $(28)$ & 13 & (12) \\
\hline 1 a 2 & $71(35)$ & 34 & $(37)$ & 38 & $(35)$ \\
\hline 3 a 4 & $47(24)$ & 22 & (24) & 25 & (23) \\
\hline 5 ou mais & $42(21)$ & 10 & (11) & 32 & $(30)$ \\
\hline Total & $200(100)$ & 92 & (100) & 108 & (100) \\
\hline
\end{tabular}

A partir dos dados obtidos ao uso de medicamentos notou-se, um total de 160 idosos de ambos os sexos que usavam algum tipo de medicamentos.

Verificou-se maior porcentagem de mulheres (88\%) usavam medicamentos, enquanto os homens mencionaram menor uso( $71 \%)$.

Em relação aos idosos que usavam 3 a 4 medicamentos, (24\%) eram do sexo masculino, e (23\%) do sexo feminino, totalizando 47 (24\%) dos idosos. Observa-se semelhança em ambos os sexos.

Mosegui et al. (1999), pesquisaram 634 mulheres idosas e encontraram que a média do número de medicamentos consumidos foi de 4,0 medicamentos/pessoa. As mulheres que faziam uso de 1 a 4 medicamentos eram em torno de 52,7\%, aquelas que utilizavam entre 5 e 10 medicamentos em 34,4\% e 3,8\% utilizavam mais de 10 medicamentos, regularmente. 
A maior parte dos medicamentos utilizados $83,8 \%$ foi prescrita por médicos, sendo o restante indicados por leigos; amigos, vizinhos, veículos de comunicação e por balconistas de farmácias e drogarias. Cerca de $17 \%$ dos medicamentos podem ser formalmente considerados inadequados para o uso nessas idosas e 14,1\% das mulheres faziam uso de medicações redundantes. Quanto às interações medicamentosas, 15,5\% das entrevistadas estavam expostas aos principais efeitos colaterais. Ressalta-se a importância de uma avaliação adequada no momento da prescrição, pois tais associações só tendem a aumentar a incidência de efeitos adversos, como as quedas.

A idade é uma variável preditora do uso de medicamentos, e seu efeito se produz mesmo antes dos 60 anos, pois a chance de usar medicamentos aumenta desde a quarta década de vida (BARDEL et al., 2000).

Tabela 3 - Distribuição dos idosos segundo sexo, uso de tabaco, álcool e pratica de atividade física. Catanduva, 2008.

\begin{tabular}{lccccc}
\hline & & \multicolumn{5}{c}{ Sexo } \\
\cline { 3 - 6 } & Total (\%) & Masculino & $(\mathbf{\%})$ & Feminino & $(\boldsymbol{\%})$ \\
\hline Tabagismo & & & & & \\
Sim & $24(12)$ & 20 & $(22)$ & 4 & $(4)$ \\
Não & $176(88)$ & 72 & $(78)$ & 104 & $(96)$ \\
Álcool & & & & & \\
Sim & $38(19)$ & 29 & $(32)$ & 9 & $(8)$ \\
Não & $162(81)$ & 63 & $(68)$ & 99 & $(92)$ \\
Atividade física & & & & & \\
Sim & $73(36)$ & 39 & $(42)$ & 34 & $(31)$ \\
Não & $127(64)$ & 53 & $(58)$ & 74 & $(69)$ \\
\hline Total & $\mathbf{2 0 0 ( 1 0 0 )}$ & $\mathbf{9 2}$ & $\mathbf{( 1 0 0 )}$ & $\mathbf{1 0 8}$ & $\mathbf{( 1 0 0 )}$ \\
\hline
\end{tabular}

Do total dos participantes entrevistados, houve uma maior porcentagem de homens tabagista $20(22 \%)$ comparado a $4(4 \%)$ das mulheres.

Já no que diz respeito ao etilismo, 29 (32\%) dos homens relataram consumir álcool e 9(8\%) das mulheres consumiam algum tipo de álcool. 
Notou-se também uma maior porcentagem de homens que realizam atividade física 39 (42\%) e nas mulheres houve uma pequena diferença de 34 (31\%).

Resultados semelhantes foram encontrados no estudo de Mosegui et al. (1999), sendo que $89,2 \%$ são sedentários, 23,3\% estilistas e 22,5\% tabagistas.

Um estudo realizado por Meirelles ( 2003), analisou 180 indivíduos, portadores de coronariopatia aterosclerótica comprovada por cineangiocoronariografia, com idade igual ou superior a 60 anos, o maior risco encontrado foi a associação de tabagismo e presença de doença arterial obstrutiva dos membros inferiores, neste caso o risco estimado é de 30,4\%, conclui-se que a prevalência de dilatação da aorta abdominal foi de 8,9\% 16, apresentou-se de forma mais freqüente nos indivíduos do sexo masculino, tabagistas, hipertensos, portadores de doença arterial obstrutiva aterosclerótica dos membros inferiores, e presença de lesões aterosclerótica difusa das artérias coronárias.

Province et al. (1995), verificaram que, dentre diversas intervenções como fortalecimento muscular, treino de flexibilidade e exercícios de resistência, a intervenção que incluía treino de equilíbrio foi a única capaz de reduzir significativamente as quedas. Para os autores, os déficits de equilíbrio poderiam ter uma relação mais direta com as quedas do que a força muscular, flexibilidade ou déficit de resistência. 
Tabela 4 - Distribuição dos idosos segundo sexo e dados relacionados quanto ao uso de óculos e aparelho auditivo. Catanduva, 2008.

\section{Sexo}

Total (\%) $\quad$ Masculino $\quad(\%) \quad$ Feminino $\quad(\%)$

\begin{tabular}{lccccc}
\hline Uso de óculos & & & & & \\
Sim - Melhora Total & $96(48)$ & 42 & $(46)$ & 54 & $(50)$ \\
Sim - Melhora Parcial & $53(27)$ & 27 & $(29)$ & 26 & $(24)$ \\
Não - Mas Necessita & $34(17)$ & 15 & $(16)$ & 19 & $(18)$ \\
Não - Não Necessita & $17(8)$ & 8 & $(9)$ & 9 & $(8)$ \\
Uso de aparelho de audição & & & & & \\
Sim - Melhora Total & $8(4)$ & 5 & $(5)$ & 3 & $(3)$ \\
Sim - Melhora Parcial & $8(4)$ & 4 & $(4)$ & 4 & $(4)$ \\
Não - Mas Necessita & $30(15)$ & 18 & $(20)$ & 12 & $(11)$ \\
Não - Não Necessita & $154(77)$ & 65 & $(71)$ & 89 & $(82)$ \\
\hline Total & $\mathbf{2 0 0 ( 1 0 0 )}$ & $\mathbf{9 2}$ & $\mathbf{( 1 0 0 )}$ & $\mathbf{1 0 8}$ & $\mathbf{( 1 0 0 )}$ \\
\hline
\end{tabular}

A partir dos dados coletados no uso de óculos e aparelho de audição, observa-se que não há diferença entre os sexos.

A disfunção vestibular assume particular importância, pois o aumento da idade é diretamente proporcional à presença de múltiplos sintomas otoneurológicos associados, tais como vertigem e outras tonturas, perda auditiva, zumbido, alterações do equilíbrio corporal, distúrbios da marcha e quedas ocasionais, entre outros (GANANÇA, CAOVILLA, 1998; TINETTI ME, WILLIAMS, GILL, 2000).

O conhecimento das características funcionais do equilíbrio em idosos com disfunção vestibular crônica e a identificação de variáveis associadas ao déficit do equilíbrio nestes indivíduos podem promover o desenvolvimento de estratégias específicas de prevenção, assistência e reabilitação, com vistas à manutenção da autonomia e preservação da independência do idoso, o maior tempo possível (Gazzola et al., 2006).

Para Pfaltz et al. (1999) a redução da visão, redução da percepção de distancia e visão periférica e adaptação ao escuro e diminuição da audição (não ouve sinais de alarme); 
distúrbios vestibulares (infecção ou cirurgia prévia do ouvido, vertigem posicional benigna, são fatores de risco intrínseco para quedas (BIRGE, 1999; BARAFF et. al., 1997).

O equilíbrio corporal depende da integridade do sistema vestibular (labirinto, nervo vestibulococlear, núcleos, vias e inter-relações no sistema nervoso central), do sistema somatossensorial (receptores sensoriais localizados em tendões, músculos e articulações) e da visão. O labirinto é responsável pelo equilíbrio e posição do corpo no espaço. Tonturas e ou desequilíbrio surgem quando algo interfere no funcionamento normal do sistema de equilíbrio corporal podendo ser de origem periférica e/ou central (Jurkiewicz et al., 2002).

Mota et al. (2002) referem que em pessoas com idade avançada, deve-se levar em conta o envelhecimento dos sistemas sensoriais, principalmente da visão, da propriocepção, dos receptores de pressão plantar e da função da orelha interna. Em todos os níveis desses sistemas produz-se uma perda de neurônio que se inicia na sexta década e se acelera depois dos 70 anos. Também no cérebro e no cerebelo ocorre uma perda neuronal. Por conseguinte, o aparelho neuronal, destinado ao equilíbrio e à função vestíbulo-oculomotora, apresenta perda gradual de velocidade e precisão, que se manifesta em forma de tontura e vertigem.

Alguns estudos relatam a perda de células ciliadas das cristas ampulares e das máculas, o declínio do número de células nervosas do gânglio de Scarpa, a degeneração das otocônias, a diminuição do fluxo sanguíneo labiríntico, a progressiva depressão da estabilidade neural, a redução na capacidade de compensação dos reflexos vestíbulo-ocular (responsável em manter a visão estável durante a movimentação cefálica) e vestíbuloespinal (responsável pela estabilização corporal) contribuem para a diminuição da velocidade dos movimentos de perseguição e para a hiporreatividade rotacional e calórica do sistema vestibular tanto a nível periférico quanto central (HAIN ET AL., 2002; SILVEIRA ET AL., 2002; WHITNEY, 2002). 


\subsection{QUEDAS}

Tabela 5 - Distribuição dos idosos segundo sexo e quedas. Catanduva, 2008.

\begin{tabular}{|c|c|c|c|c|c|}
\hline & \multirow[b]{2}{*}{ Total $(\%)$} & \multicolumn{4}{|c|}{ Sexo } \\
\hline & & Masculino & $(\%)$ & Feminino & $(\%)$ \\
\hline \multicolumn{6}{|c|}{ Queda nos últimos 6 meses } \\
\hline Sim & $102(51)$ & 42 & $(46)$ & 60 & $(56)$ \\
\hline Não & $98(49)$ & 50 & (54) & 48 & (44) \\
\hline
\end{tabular}

Frequiência das quedas

$\begin{array}{lccccc}\text { Sempre } & 13(6) & 3 & (3) & 10 & (9) \\ \text { Às vezes } & 25(13) & 10 & (11) & 15 & (14) \\ \text { Raramente } & 88(44) & 39 & (42) & 49 & (45) \\ \text { Nunca } & 74(37) & 40 & (43) & 34 & (32)\end{array}$

Largura dos passos

$\begin{array}{llllll}\text { Pequeno } & 135(68) & 52 & (57) & 83 & (77) \\ \text { Grande } & 65(32) & 40 & (43) & 25 & (23)\end{array}$

Simetria da marcha

$\begin{array}{llllll}\text { Simétrica } & 125(63) & 66 & (72) & 59 & (55) \\ \text { Assimétrica } & 75(37) & 26 & (27) & 49 & (46) \\ \text { raqueza muscular } & & & & & \\ \text { Sim } & 45(23) & 21 & (23) & 24 & (22) \\ \text { Não } & 120(60) & 54 & (59) & 66 & (61) \\ \text { Às vezes } & 35(17) & 17 & (18) & 18 & (17)\end{array}$

Problema nos pés

\begin{tabular}{|c|c|c|c|c|c|}
\hline Não apresenta & $155(78)$ & 71 & (77) & 84 & (78) \\
\hline Apresenta & $45(10)$ & 21 & (23) & 36 & (23) \\
\hline Total & $200(100)$ & 92 & (100) & 108 & (100) \\
\hline
\end{tabular}


A Tabela 5 mostra que 102 (51\%) indivíduos caíram nos últimos 6 meses, 42 (46\%) do sexo masculino e 60(56\%) do sexo feminino, sendo que 88 (44\%) dos indivíduos relataram que raramente sofriam quedas. Em relação à largura dos passos 135 (68\%) relataram ter passos pequenos, 125 (63\%) dos idosos apresentaram marcha simétrica, 120 (60\%) dos indivíduos sentiam fraqueza muscular e 155 (78\%) apresentavam problemas nos pés.

Em investigação realizada por Ferreira (2006), como parte do estudo multicêntrico Saúde-Bem-estar e Envelhecimento (SABE), coordenado pela Organização Pan-Americana de Saúde (OPAS), no período de 1997 a 2003, cujo objetivo foi traçar o perfil dos idosos na América Latina e no Caribe, foi encontrado que as quedas assumem o segundo lugar entre muitos idosos, 40,7\% dos idosos sofreram quedas nos últimos meses a pesquisa, sendo que $22,0 \%$ sofreram mais que 3 quedas nesse período.

As quedas raramente tem uma única causa ou fator de risco, sendo usualmente causadas por uma série de fatores extrínsecos e intrínsecos e situacionais. (MERCK, 2005).

\subsection{Condições Extrínsecas}

Tabela 6 - Distribuição dos idosos segundo sexo e condições extrínsecas da queda. Catanduva, 2008 ( $\mathrm{n}=102)$.

\begin{tabular}{lccccc}
\hline & & \multicolumn{5}{c}{ Sexo } \\
\cline { 5 - 6 } & Total (\%) & Masculino & $(\%)$ & Feminino & $(\%)$ \\
\hline Local da queda & & & & & \\
Dentro de casa & $39(38)$ & 17 & $(40)$ & 22 & $(37)$ \\
$\quad$ Fora de casa & $63(62)$ & 25 & $(60)$ & 38 & $(63)$ \\
Piso no Local & & & & & \\
Liso & $40(39)$ & 18 & $(43)$ & 22 & $(36)$ \\
Áspero & $58(57)$ & 23 & $(55)$ & 35 & $(58)$ \\
Outros & $2(2)$ & 1 & $(2)$ & 1 & $(2)$ \\
Não sabe & $1(1)$ & 0 & - & 1 & $(2)$ \\
Não respondeu & $1(1)$ & 0 & - & 1 & $(2)$ \\
\hline
\end{tabular}




\begin{tabular}{lccccc}
\hline Estado do Piso & & & & & \\
Seco & $70(69)$ & 30 & $(71)$ & 40 & $(66)$ \\
Molhado & $27(26)$ & 12 & $(29)$ & 15 & $(25)$ \\
Encerado & $1(1)$ & 0 & - & 1 & $(2)$ \\
Buraco no chão & $3(3)$ & 0 & - & 3 & $(5)$ \\
Outros & $1(1)$ & 0 & - & 1 & $(2)$
\end{tabular}

Havia degraus

$\begin{array}{llllll}\text { Sim } & 30(29) & 14 & (33) & 16 & \text { (27) } \\ \text { Não } & 72(71) & 28 & (67) & 44\end{array}$

Iluminação no local

$\begin{array}{lccccc}\text { Claro } & 92(90) & 38 & (90) & 54 & (90) \\ \text { Escuro } & 10(10) & 4 & (10) & 6 & (10)\end{array}$

Horário da queda

$\begin{array}{lccccc}\text { Manhã } & 51(50) & 21 & (50) & 30 & (50) \\ \text { Almoço } & 10(10) & 7 & (17) & 3 & (5) \\ \text { À tarde } & 24(23) & 7 & (17) & 17 & (28) \\ \text { Fim da tarde } & 5(5) & 3 & (7) & 2 & (3) \\ \text { Noite } & 12(12) & 4 & (9) & 8 & (13)\end{array}$

Havia tapete no local

$\begin{array}{cccccc}\text { Sim } & 3(3) & 1 & (2) & 2 & \text { (3) } \\ \text { Não } & 99(97) & 41 & (98) & 58 & \text { (97) }\end{array}$

Calçado usado

\begin{tabular}{lccccc} 
Sapato fechado & $31(30)$ & 18 & $(43)$ & 13 & $(22)$ \\
Chinelo & $44(43)$ & 12 & $(29)$ & 32 & $(53)$ \\
Sandália & $14(14)$ & 4 & $(9)$ & 10 & $(17)$ \\
Outros & $13(13)$ & 8 & $(19)$ & 5 & $(8)$ \\
& & & & & \\
\hline otal & $\mathbf{1 0 2}(\mathbf{1 0 0})$ & $\mathbf{4 2}$ & $\mathbf{( 1 0 0 )}$ & $\mathbf{6 0}$ & $\mathbf{( 1 0 0 )}$ \\
\hline
\end{tabular}


Com relação ao local da queda, 63 (62\%) dos idosos relataram ter caído fora de casa, sendo que as mulheres $38(63 \%)$ caem mais que os homens sendo que $35(58 \%)$ das mulheres idosas caiam em piso áspero, e 70 (69\%) dos idosos caiam em piso seco e que não haviam degraus 72 (71\%). Quanto à iluminação do local, 92 (90\%) disseram que estava claro e mencionaram ter caído no período da manhã (50\%), a maioria, (97\%) dos idosos, relataram não ter tapetes no local da queda e estarem de chinelo 44 (43\%).

Com o aumento da freqüência de quedas em idosos fora de casa, os municípios deveriam se preocupar em realizar melhorias nas calçadas, proporcionando maior acessibilidade para que os idosos possam desenvolver suas atividades diárias sem maiores riscos.

Segundo Oliveira (2002), as quedas predominaram no sexo feminino $(31,1 \%)$, indicando uma maior incidência 2,11 nas mulheres comparadas aos homens.

Quanto ao uso de chinelo, (84\%) dos idosos estavam de chinelo no momento da queda, foi encontrado semelhança em relação ao estado do piso, que apresentava-se seco em $(65,4 \%)$ dos casos.

Para Carvalho, Coutinho, (2002), a maior parte das quedas ocorreram em ambientes claro.

No estudo de Lojudice, (2005), os idosos não relataram à presença de tapetes no local da queda. 


\subsection{Condições intrínsecas}

Tabela 7 - Distribuição dos idosos segundo sexo e o grupo de medicamentos consumidos. Catanduva, 2008.

\begin{tabular}{lcccccc}
\hline & & \multicolumn{5}{c}{ Sexo } \\
\cline { 4 - 7 } Uso de medicamentos & \multicolumn{2}{c}{ Total } & Masculino & $(\%)$ & Feminino & \\
& $(\mathbf{n}=\mathbf{2 0 0})$ & $(\boldsymbol{\%})$ & $(\mathbf{n = 9 2})$ & & $(\mathbf{n = 1 0 8})$ & $(\%)$ \\
\hline Anti-hipertensivos & 59 & $(30)$ & 28 & $(30)$ & 31 & $(29)$ \\
Antiglicemiantes & 9 & $(5)$ & 3 & $(3)$ & 6 & $(6)$ \\
Antivertiginoso & 11 & $(6)$ & 0 & - & 11 & $(10)$ \\
Diuréticos & 20 & $(10)$ & 8 & $(9)$ & 12 & $(11)$ \\
Antidislipidemicos & 6 & $(3)$ & 2 & $(2)$ & 4 & $(4)$ \\
Controlados & 13 & $(7)$ & 4 & $(4)$ & 9 & $(8)$ \\
Outros & 76 & $(38)$ & 33 & $(36)$ & 43 & $(40)$ \\
Não sabem ou não & 94 & $(47)$ & 47 & $(51)$ & 47 & $(44)$ \\
usam medicamentos & & & & & & \\
\hline
\end{tabular}

Pode-se observar na Tabela 7, que os medicamentos mais utilizados pelos idosos foram os Anti-hipertensivos 59 (30\%), sendo nos homens o consumo foi de (30\%), houve diferença mínima em relação às mulheres $(29 \%)$.

Encontrou-se que 94 (47\%) dos idosos faziam uso de algum tipo de medicamento, mas não sabiam o nome.

Num estudo realizado por Schroeter et al. (2007), utilizando uma ficha de seguimento farmacológico, foram entrevistados 385 idosos, dos quais $(62,3 \%)$ utilizavam medicamentos com ação no sistema cardiovascular, sendo que destes, 83,6\% utilizavam anti-hipertensivos, $59,4 \%$ diuréticos, e 51,2\%,inibidores da enzima conversora da angiotensina (ECA), sendo os anti-hipertensivos mais utilizados, de acordo com a classificação da Organização Mundial de Saúde/Sociedade Internacional de Hipertensão. Os resultados mostraram, que dos pacientes entrevistados, 330 ( $85,71 \%$ ) usavam um ou mais tipos de medicamentos, enquanto que 55 $(14,29 \%)$ não faziam uso de terapia medicamentosa. 
No estudo de Coutinho e Silva (2002), para avaliar o uso de medicamentos como fator de risco de quedas entre pessoas de 60 anos ou mais, no qual encontraram um aumento no risco de quedas para o uso de drogas bloqueadoras dos canais de cálcio, benzodiazepínicos e vasodilatadores.

Outros estudos também encontraram semelhança no uso de medicamentos em idosos como nos trabalhos de Coelho; Marcopito; Castelo (2004), Flores; Mengue (2005).

Segundo Tinetti et al. (1994) e Robbins et al. (1989), as quedas foram mais frequientes entre idosos que faziam uso de 4 ou mais fármacos.

Tabela 8 - Distribuição dos idosos segundo sexo e dados relatados sobre o que o participante atribuiu a queda. Catanduva, $2008(\mathrm{n}=102)$.

\begin{tabular}{lccccc}
\hline & & \multicolumn{4}{c}{ Sexo } \\
\cline { 3 - 6 } Atribuição da Queda & Total (\%) & Masculino & $\mathbf{( \% )}$ & Feminino & $\mathbf{( \% )}$ \\
\hline Alterações externas & $61(61)$ & 26 & $(61)$ & 35 & $(59)$ \\
Alterações internas & $35(35)$ & 13 & $(30)$ & 22 & $(37)$ \\
Não sabe & $6(6)$ & 3 & $(7)$ & 3 & $(5)$ \\
\hline Total & $\mathbf{1 0 2 ( 1 0 0 )}$ & $\mathbf{4 2}$ & $\mathbf{( 1 0 0 )}$ & $\mathbf{6 0}$ & $\mathbf{( 1 0 0 )}$ \\
\hline
\end{tabular}

$\mathrm{Na}$ Tabela 8 observa-se que, 61(61\%) dos idosos relataram que caíram por alterações externas, e que $6 \%$ dos idosos não sabem porque caíram.

Segundo alguns autores, se tratando de alterações do equilíbrio na população idosa, é de causa multifatorial, uma vez que existem inúmeros fatores de risco concorrentes, como a presença de doenças cardiovasculares, neurológicas, músculo-esqueléticas, diabetes, síncopes de origem idiopática, uso de diferentes classes de drogas, incluindo diuréticos, anticonvulsivantes, antihipertensivos, ansiolíticos e antidepressivos (TILVIS et al. 1996, ENSRUD et al. 1992, COLLEDGE et al. 1994).

É necessária a abordagem de uma equipe multidisciplinar (otorrinolaringologistas, geriatras, cardiologistas, fonoaudiólogos, fisioterapeutas) para obterse a completa reabilitação do desequilíbrio nesses pacientes minimizando assim os riscos e 
morbidades associados às quedas e ao isolamento social do indivíduo (SIMOCELI et al. 2003).

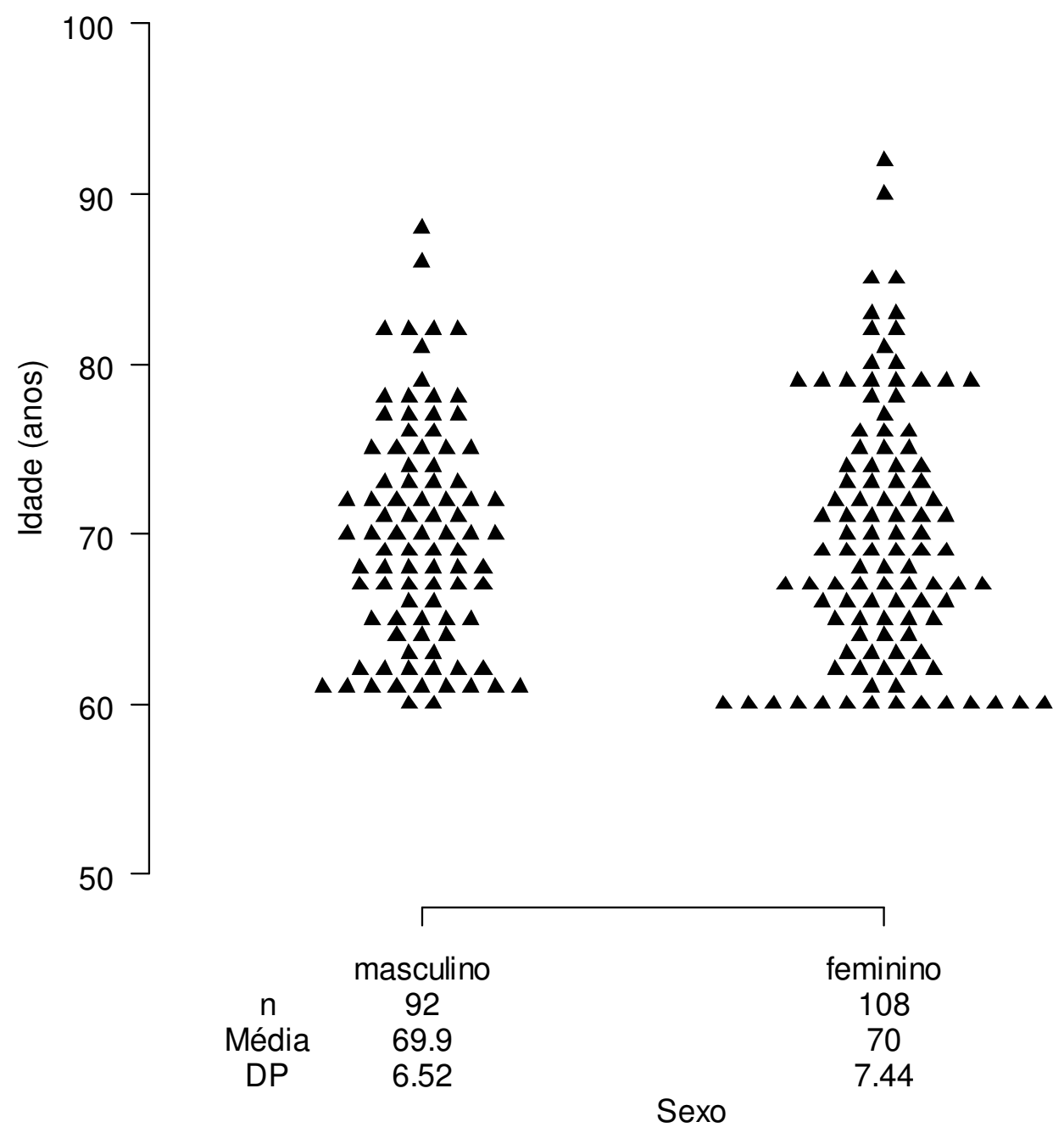

Figura 1 - Distribuição da idade (em anos completos) dos idosos, segundo o sexo. Catanduva, 2008 .

Houve uma semelhança nas idades dos indivíduos do sexo feminino e do sexo masculino, uma média de 69,9 de idosos sexo masculino e uma média de 70 idosos do sexo feminino.

Estudos similares foram realizados por Paula (2007), Nakano (2007), Miller et al. (2008), os quais avaliaram idosos de 60 anos ou mais de ambos os sexos. 


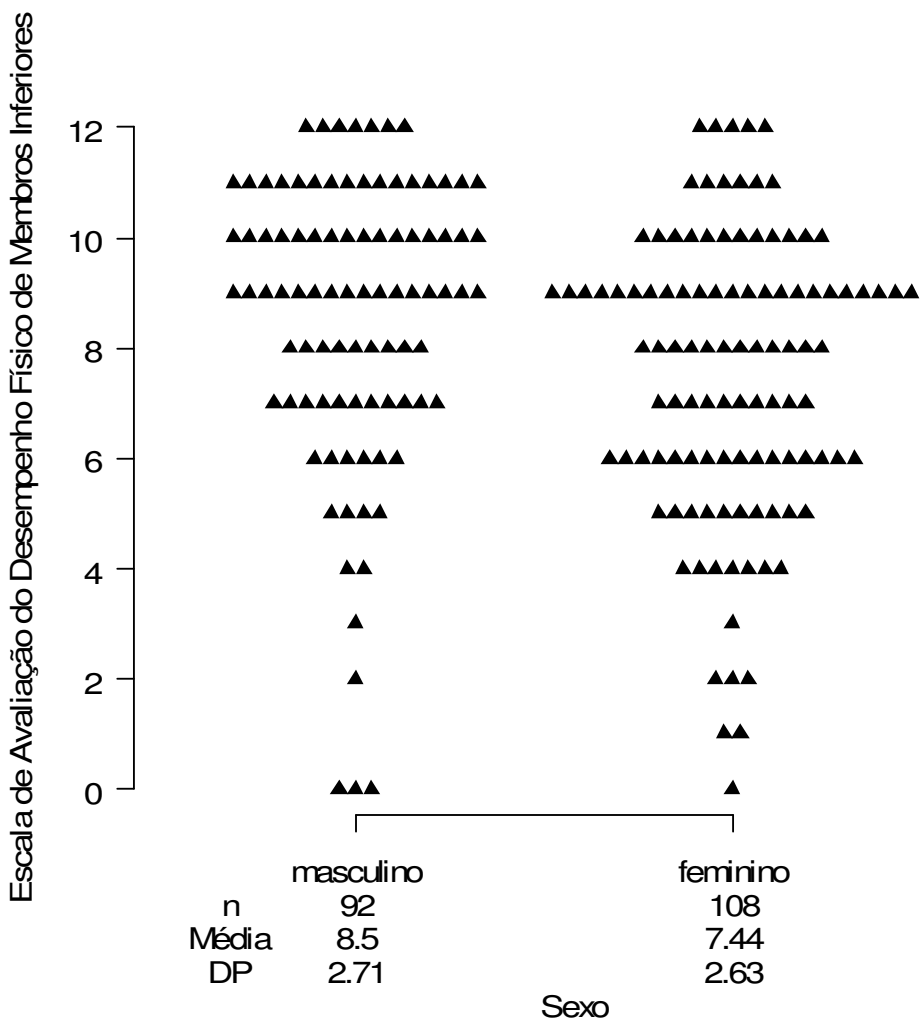

Figura 2 - Distribuição dos valores obtidos pelos idosos na Escala de Avaliação do Desempenho Físico de Membros Inferiores, segundo o sexo. Catanduva, 2008

Observa-se que na escala de desempenho físico de membros inferiores, que há um maior número de indivíduos do sexo feminino n 108 sendo, uma média de idade de 8,5 para os homens e 7,44 para as mulheres e um desvio padrão de 2,71 no sexo masculino e 2,63 no sexo feminino.

Rubenstein e Josephson (2002), analisando 16 estudos com idosos vivendo na comunidade e com idosos institucionalizados, apontam um aumento do risco com a presença dos seguintes fatores, por ordem de importância: presença de fraqueza muscular, história de quedas, déficit de marcha e de equilíbrio, uso de dispositivo de auxílio à marcha, déficit visual, artrite, comprometimento em atividades de vida diária, depressão, declínio cognitivo e idade igual ou superior a 80 anos.

Wiksten et al. (1996) encontraram uma relação positiva e estatisticamente significante entre a força muscular de MMII e desempenho nas tarefas de equilíbrio, em 
estudo comparando um grupo de idosos com um grupo controle de adultos jovens, concluíram que o aumento da força muscular dos MMII pode ser importante para os idosos manterem o controle postural em situações variadas, sugerindo dessa forma, uma redução no risco de quedas.

Em um estudo realizado por Madureia (2007), utilizando 66 mulheres idosas, concluise, que uma intervenção utilizando o treino de equilíbrio é extremamente efetiva na melhora do equilíbrio funcional e estático, da mobilidade e diminuição das quedas em mulheres idosas com osteoporose.

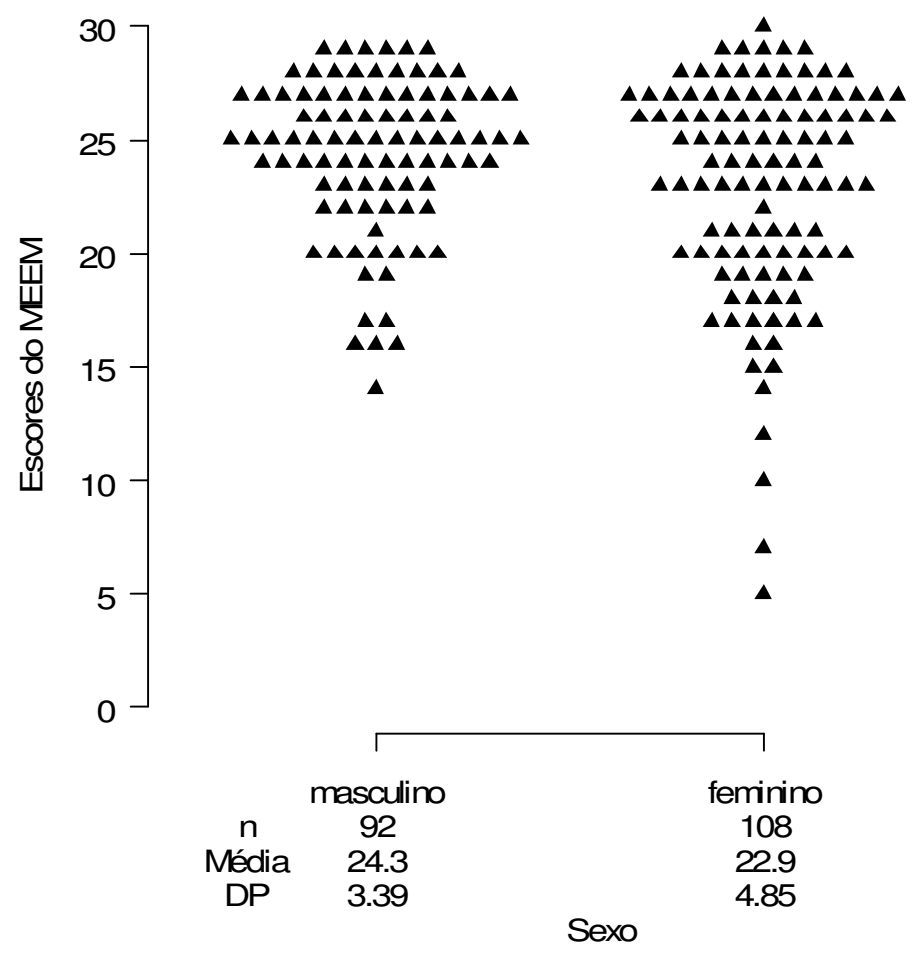

Figura 3 - Distribuição dos escores do MEEM dos idosos, segundo o sexo. Catanduva, 2008.

A Figura 3, mostra que os escores do MEEM, não se diferenciam entre os sexos, sendo que apresentaram (92) individuos do sexo masculino, e (108) do sexo feminino, uma média de $(24,3)$ no sexo masculino, e de $(22,9)$ sexo feminino, sendo um DP de $(3,39)$ para os participantes do sexo masculino e DP $(4,85)$ para os participantes do sexo feminino.

Um estudo realizado por Laks et al. (2003), no município de Santo Antonio de Pádua/RJ, avaliaram-se idosos residentes na comunidade utilizando o MEEM. Dividindo a 
amostra em idosos jovens (65-84 anos) e idosos velhos ( $>85$ anos) e escolaridade (analfabetos, alfabetizados) e concluíram, que a escolaridade e idade influenciam o MEEM. Estes resultados não se comparam aos de países desenvolvidos pela variável educação. Entretanto, sabe-se que o desempenho depende muito da escolaridade do indivíduo e, para minimizar este efeito, recomenda-se a utilização de pontos de corte distintos conforme o nível educacional.

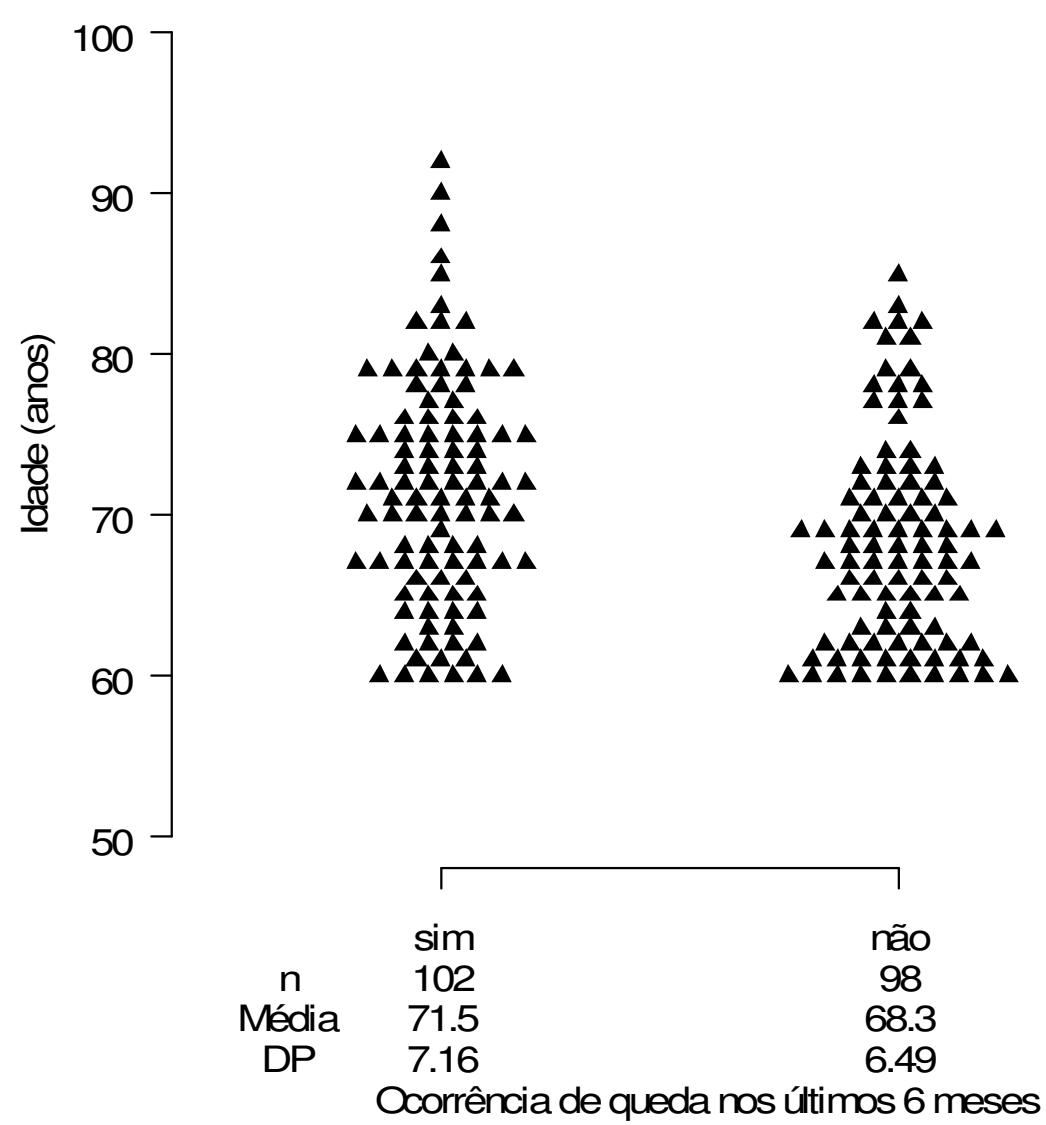

Figura 4 - Distribuição de idade dos idosos e ocorrência de Quedas nos últimos 6 meses. Catanduva, 2008.

Como pode-se observar, na Figura 4, os indivíduos que sofreram quedas 102, apresentaram média de idade mais elevada , em comparação aos indivíduos que não sofreram quedas.

Um estudo realizado por Couto, Perracini (2006) no município de ITU/MG, com 150 idosos com 65 anos e mais. Utilizou-se uma entrevista semi-estruturada e os instrumentos Brazilian OARS Multidimensional Functional Assessment Questionnaire (BOMFAQ), 
Geriatric Depression Scale (GDS), MEEM e "Timed up and go test". Observou-se que mais de $66 \%$ dos sujeitos desta pesquisa estavam com idade inferior a 75 anos, assemelhando-se aos dados de González et al. de 2001 69,5\% encontrou-se predomínio do sexo feminino como em outros estudos como o de Fabrício et al. (2004) 66\%, de González et al. 2001 87,8\%, de Ramos et al (1998) 65\%, Graafmans et al. (1996) 85\% e de Ramos et al. (1993) 60\%.

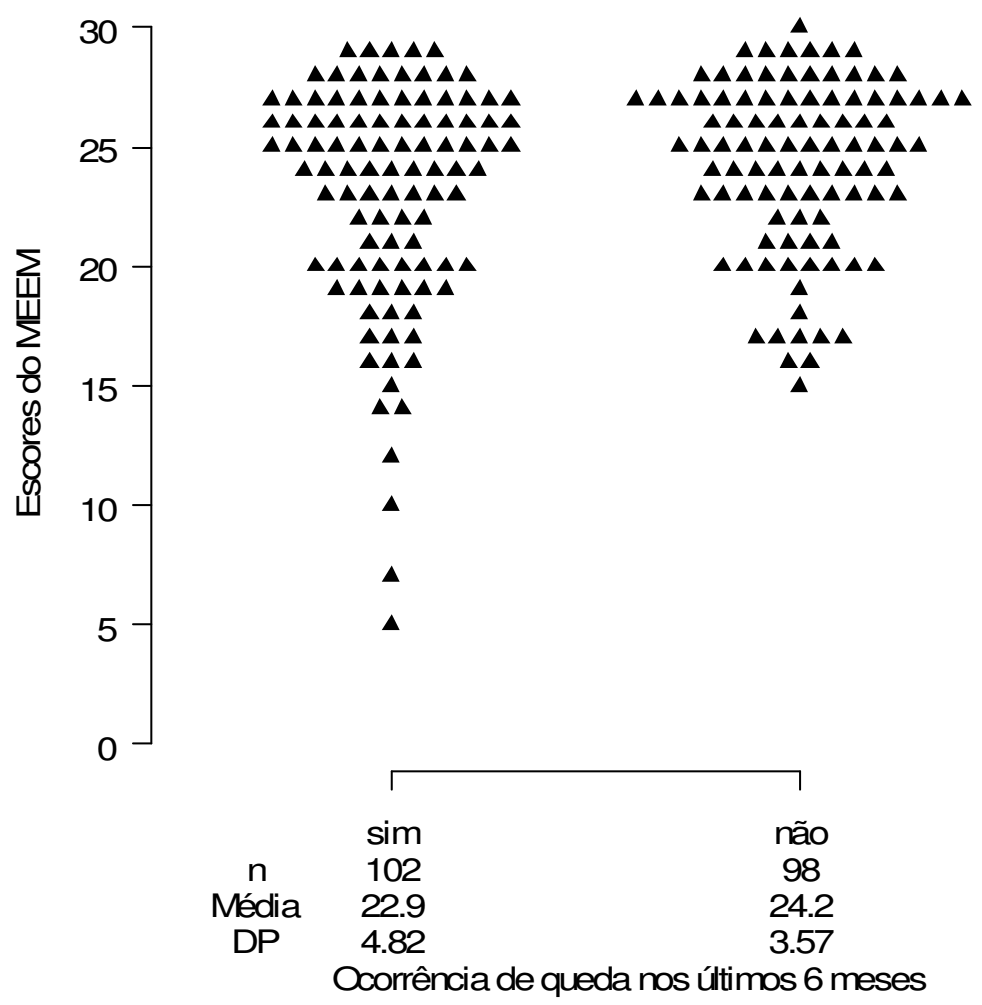

Figura 5 - Distribuição dos idosos segundo o MEEM e Ocorrência de quedas nos últimos 6 meses. Catanduva, 2008.

Analisando a Figura 5, pode-se observar, que grande parte dos participantes obtiveram um escore superior a 15 no MEEM, no entanto os indivíduos que não sofreram queda, obtiveram uma média superior aos indivíduos que sofreram quedas, no que diz respeito ao escore do MEEM.

Um estudo realizado por Gratão et al. (2003), observou-se que ocorreu maior número de quedas entre as idosas, pois dos 31 idosos que sofreram quedas 19 61,2\% eram do sexo feminino e 12 38,8\% era do sexo masculino. Considerando que os idosos estão expostos a várias situações, que podem levar á perda da autonomia e independência, principalmente em 
portadores de Demência, estes estão sujeitos também à perda do equilíbrio, pela dificuldade de manterem a postura, aumentando assim, o risco para a ocorrência de quedas.

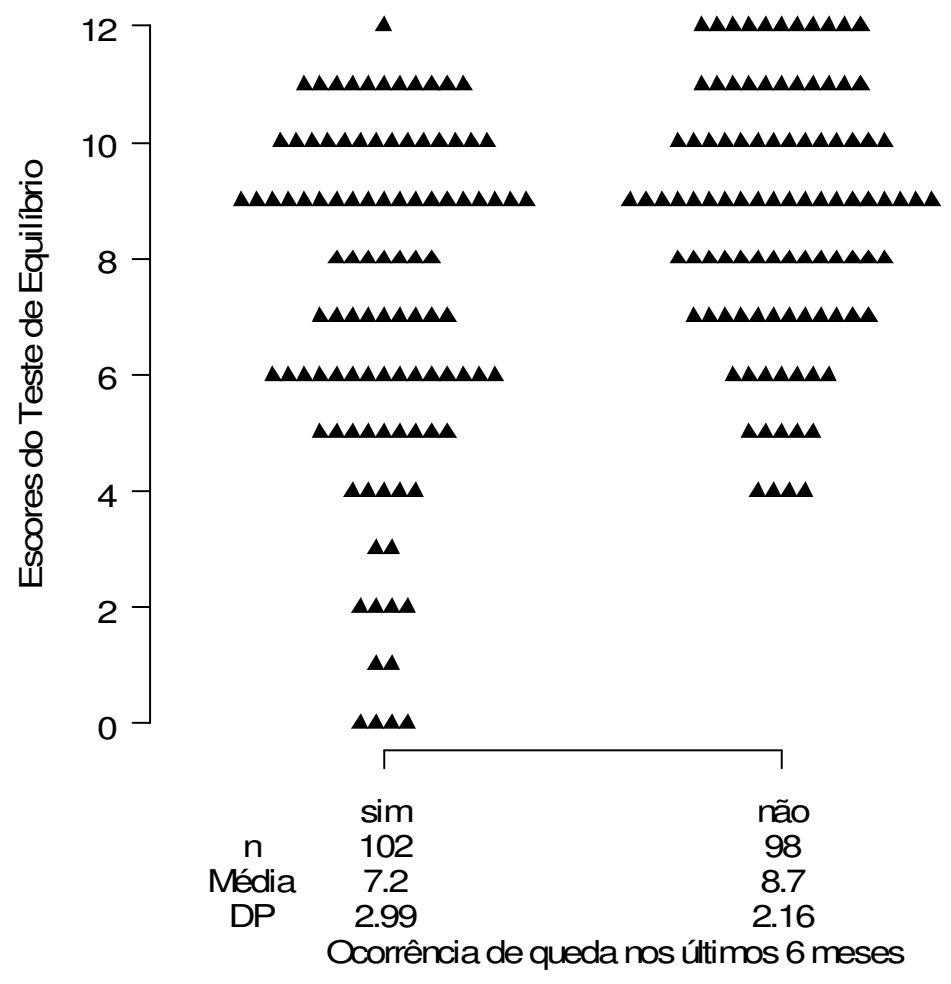

Figura 6 -Distribuição dos Escores do teste do equilíbrio e Ocorrência de quedas nos idosos nos últimos 6 meses. Catanduva, 2008.

Ao observar a Figura 6, nota-se que grande parte dos indivíduos que não apresentaram ocorrência de quedas, obtiveram uma média superior aos indivíduos que apresentaram ocorrência de quedas.

Em um estudo realizado por Guralnik et al. (2000), com 4.588 indivíduos com idade maior de 65 anos e com independência funcional, foi constatado que o teste isolado da avaliação da marcha, quando comparado ao escore total do SPPB, prediz grande valor quanto ao risco de incapacidade nas AVDs e risco de desenvolver limitações importantes no fator mobilidade, em um período de quatro anos. O mesmo foi demonstrado por Nakano (2007), propôs uma adaptação cultural da Versão Brasileira do SPPB, com o objetivo de avaliar a confiabilidade deste instrumento para a população idosa brasileira. $\mathrm{O}$ estudo obteve resultados 
que confirmam a validade e confiabilidade deste instrumento em outras análises psicométricas. Todos os estudos citados relatam que a aplicação da SPPB apresenta resultado mais significativo quando avaliado na íntegra com todos os domínios e o respectivo escore total, pois possibilita uma abordagem mais ampla quanto aos aspectos do status funcional dos idosos (OSTIR et al., 1998; GURALNIK et al., 2000; ROLLAND et al., 2006).

Com relação ao estudo realizado por Mantovani (2007), pesquisou 120 idosos de ambos os sexos, sendo 47 homens e 73 mulheres, com idade média de 77,13 $\pm 7,6$, utilizou a SPPB, onde foi observado diferenças com significância estatística encontradas nas variáveis: marcha, força de membros inferiores e total do SPPB, em que os maiores escores estavam entre os idosos ativos e concluíram, que a atividade física regular pode diminuir a velocidade de declínio do desempenho físico, em relação à mobilidade, independentemente da idade cronológica. A manutenção de um nível funcional de independência pode melhorar a saúde e a qualidade de vida no envelhecimento.

Tabela 9 - Razão de incidência de quedas nos últimos 6 meses, ajustado por idade e uso de medicamentos, sexo e uso de medicamentos, sexo, idade e uso de medicamentos e por sexo e idade. Catanduva, 2008.

\begin{tabular}{|c|c|c|c|c|c|c|c|}
\hline & \multirow[b]{2}{*}{ Total } & \multicolumn{2}{|c|}{$\begin{array}{l}\text { Incidência } \\
\text { de quedas }\end{array}$} & \multirow{2}{*}{$\begin{array}{c}\text { RI } \\
\text { bruta }\end{array}$} & \multirow{2}{*}{$\begin{array}{c}\mathbf{p} \\
\text { valor }\end{array}$} & \multirow{2}{*}{$\begin{array}{l}\text { RI ajustada } \\
\text { (IC 95\%) }\end{array}$} & \multirow{2}{*}{$\begin{array}{c}\text { p } \\
\text { Valor }\end{array}$} \\
\hline & & $\mathbf{n}$ & $(\%)$ & & & & \\
\hline \multicolumn{8}{|l|}{ Sexo } \\
\hline Masculino & 92 & 42 & (46) & Ref. & & Ref. & \\
\hline Feminino & 108 & 60 & $(56)$ & 1,2 & 0,17 & $1,2(0,91,5)^{\S}$ & 0,18 \\
\hline \multicolumn{8}{|l|}{ Idade (anos) } \\
\hline 60 a 64 & 50 & 19 & (38) & Ref. & & Ref. & \\
\hline 65 a 69 & 52 & 20 & (39) & 1,0 & 0,96 & $1,0(0,61,6)^{\&}$ & 0,98 \\
\hline 70 a 74 & 47 & 28 & $(60)$ & 1,6 & 0,04 & $1,5(1,02,3)^{\&}$ & 0,06 \\
\hline 75 a 79 & 33 & 24 & (73) & 1,9 & $<, 01$ & $1,8(1,22,8)^{\&}$ & $<, 01$ \\
\hline$\geq 80$ & 18 & 11 & (61) & 1,6 & 0,07 & $1,5(0,92,5)^{\&}$ & 0,12 \\
\hline
\end{tabular}


Reside sozinho

\begin{tabular}{|c|c|c|c|c|c|c|}
\hline Sim & 30 & 21 & (70) & 1,5 & $<, 01$ & $1,3(0,91,8) *$ \\
\hline Não & 170 & 81 & $(48)$ & Ref. & & Ref. \\
\hline
\end{tabular}

Possui companheiro(a)

\begin{tabular}{|c|c|c|c|c|c|c|}
\hline Sim & 119 & 52 & (44) & Ref. & & Ref. \\
\hline Não & 81 & 50 & (62) & 1,4 & 0,01 & $1,3(0,91,7)^{*}$ \\
\hline
\end{tabular}

Usa medicamentos

$\begin{array}{cccccccc}\text { Sim } & 160 & 88 & (55) & 1,6 & 0,05 & 1,3(0,82,1)^{* *} & 0,22 \\ \text { Não } & 40 & 14 & (35) & \text { Ref. } & \text { Ref. } & \end{array}$

$\mathrm{N}^{\mathrm{o}}$ de Medicamentos

\begin{tabular}{llllllll}
0 & 39 & 14 & $(36)$ & Ref. & \multicolumn{3}{c}{ Ref. } \\
1 a 2 & 72 & 32 & $(44)$ & 1,2 & 0,40 & $1,1(0,71,8)^{* *}$ & 0,66 \\
3 a 4 & 47 & 28 & $(60)$ & 1,7 & 0,04 & $1,4(0,92,3)$ & 0,14 \\
5 ou mais & 42 & 28 & $(67)$ & 1,9 & 0,01 & $1,5(0,92,4)$ & 0,10
\end{tabular}

Pratica esportes

\begin{tabular}{|c|c|c|c|c|c|c|}
\hline Sim & 73 & 34 & $(47)$ & Ref. & & Ref. \\
\hline Não & 127 & 68 & (54) & 1,1 & 0,35 & $1,0(0,7 \quad 1,3){ }^{*}$ \\
\hline
\end{tabular}

Tabagismo

$\begin{array}{cccccccc}\text { Sim } & 24 & 14 & (58) & 1,2 & 0,41 & 1,5(1,02,3) * & 0,06 \\ \text { Não } & 176 & 88 & (50) & \text { Ref. } & \text { Ref. } & \end{array}$

RI: razão de incidência de quedas nos últimos 6 meses.

$\S$ Ajustado por idade e uso de medicamentos.

\& Ajustado por sexo e uso de medicamentos.

* Ajustado por sexo, idade e uso de medicamentos.

** Ajustado por sexo e idade. 
Dentre os idosos do sexo masculino 42 sofreram queda correspondendo `a (46\%) e no sexo feminino foram relatados uma incidência de quedas de $(56 \%)$, e um valor de p igual a 0,17 , totalizando 102 idosos que sofreram quedas, resultados semelhantes foram encontrados no estudo de Siqueira et al. (2007) e Telles, 2008.

Quanto à idade no grupo de 60 a 64 anos composto por 50 pessoas, encontrou-se 19 quedas ou seja, (38\%) dos idosos relataram os participantes 65 a 69 anos, apresentaram 52 idosos de ambos os sexos, com incidência de quedas (39\%), já os idosos de 70 a 74 , apresentaram uma incidência de quedas de (60\%) e um valor de p de 0,04, os idosos de 75 a 79 apresentaram uma incidência de quedas de (73\%) e um valor de $\mathrm{p}<, 01$, quantos aos idosos de 80 anos ou mais, totalizaram 18 idosos, e incidência de quedas de (61\%).

Em relação ao quesito com quem reside 170 idosos relataram que residem com alguma ou mais de uma pessoa e somente 30 relataram viver só e apresentaram uma incidência de quedas de $(70 \%)$ e um valor de $\mathrm{p}<01$.

No que diz respeito aos idosos que possuem companheiro(a), 119 idosos relataram possuírem companheiro(a), e somente 81 idosos relataram não ter companheiro(a), e apresentaram uma incidência de quedas de (62\%) e um valor de p de 0,01.

A respeito do uso de medicamentos 160 idosos relataram fazer uso de medicamentos, e apresentaram uma incidência de quedas de (55\%) e um valor de p de 0,05, com relação ao numero de medicamentos, 39 idosos relataram não fazerem uso de nenhum medicamento e apresentaram uma incidência de quedas de (36\%), um total de 72 idosos de ambos os sexos relataram usar 1 a 2 medicamentos, uma incidência de quedas de (44\%) e um valor de p de 0,66.Os idosos que ingeriam de 3 a 4 medicamentos, totalizaram 47 idosos e apresentaram uma incidência de quedas de $(60 \%)$ e um valor de p 0,04. Já os idosos que faziam uso de 5 ou mais medicamentos, apresentaram uma incidência de quedas de $(47 \%)$ e um valor de p de 0,01 .

Quantos aos idosos que faziam atividade física 127 idosos relataram não realizar nenhum tipo de atividade física, apresentaram 68 e uma incidência de quedas de (54\%).

Os idosos que faziam uso de cigarro, apresentaram uma incidência de quedas de $(58 \%)$. 
Tabela 10- Razão de incidência de quedas nos idosos nos últimos 6 meses, ajustado por sexo, idade e uso de medicamentos. Catanduva, 2008.

\begin{tabular}{|c|c|c|c|c|c|c|c|}
\hline & \multirow[b]{2}{*}{ Total } & \multicolumn{2}{|c|}{$\begin{array}{l}\text { Incidência } \\
\text { de quedas }\end{array}$} & \multirow{2}{*}{$\begin{array}{c}\text { RI } \\
\text { bruta }\end{array}$} & \multirow{2}{*}{$\begin{array}{c}\text { p } \\
\text { valor }\end{array}$} & \multirow{2}{*}{$\begin{array}{c}\text { RI ajustada } \\
\text { (IC 95\%) }\end{array}$} & \multirow{2}{*}{$\begin{array}{c}\mathbf{p} \\
\text { Valor }\end{array}$} \\
\hline & & $\mathbf{n}$ & $(\%)$ & & & & \\
\hline \multicolumn{8}{|c|}{ Etilismo } \\
\hline Sim & 38 & 15 & (39) & Ref. & & Ref. & \\
\hline Não & 162 & 87 & $(54 \%)$ & 1,4 & 0,15 & $1,1\left(\begin{array}{lll}0,7 & 1,7\end{array}\right)^{*}$ & 0,65 \\
\hline
\end{tabular}

Uso de óculos

\begin{tabular}{|c|c|c|c|c|c|c|c|}
\hline Sim, melhora total & 96 & 43 & (45) & Ref. & & Ref. & \\
\hline Sim, melhora parcial & 53 & 29 & (55) & 1,2 & 0,24 & $1,0(0,72,0){ }^{*}$ & 0,98 \\
\hline Não, mas necessita & 34 & 20 & (59) & 1,3 & 0,14 & $1,3(0,91,8)^{*}$ & 0,18 \\
\hline Não, não necessita & 17 & 10 & (59) & 1,3 & 0,24 & $1,3\left(\begin{array}{ll}0,8 & 1,4\end{array}\right)^{*}$ & 0,22 \\
\hline
\end{tabular}

Fraqueza muscular

\begin{tabular}{|c|c|c|c|c|c|c|}
\hline Sim & 45 & 33 & (73) & 1,9 & $<, 01$ & $1,6(1,22,2) *$ \\
\hline Às vezes & 35 & 22 & (63) & 1,6 & $<, 01$ & $1,7(1,22,4)^{*}$ \\
\hline Não & 120 & 47 & (39) & Ref. & & Ref. \\
\hline
\end{tabular}

Largura dos passos

$\begin{array}{lccccccc}\text { Pequena } & 135 & 75 & (56) & 1,3 & 0,08 & 1,2\left(\begin{array}{lll}0,8 & 1,6\end{array}\right)^{*} & 0,36 \\ \text { Grande } & 65 & 27 & (42) & \text { Ref. } & \text { Ref. } & \end{array}$

Simetria da marcha

\begin{tabular}{|c|c|c|c|c|c|c|c|}
\hline Simétrica & 125 & 58 & (46) & Ref. & & Ref. & \\
\hline Outras & 75 & 44 & (59) & 1,3 & 0,09 & $1,0(0,7 \quad 1,4)^{*}$ & 0,96 \\
\hline \multicolumn{8}{|c|}{ roblema nos pés } \\
\hline Apresenta & 45 & 28 & (62) & 1,3 & 0,07 & $1,2(0,91,5)^{*}$ & 0,23 \\
\hline Não apresenta & 155 & 74 & (48) & Ref. & & Ref. & \\
\hline
\end{tabular}


Uso de aparelho de audição

$\begin{array}{lccccccc}\text { Sim, melhora total } & 8 & 5 & (63) & 1,4 & 0,23 & 1,2\left(\begin{array}{ll}0,7 & 2,1\end{array}\right) & * \\ \text { Sim, melhora parcial } & 8 & 6 & (75) & 1,7 & 0,02 & 1,6\left(\begin{array}{lll}1,0 & 2,6\end{array}\right) & 0,06 \\ \text { Não, mas necessita } & 30 & 23 & (77) & 1,7 & <, 01 & 1,5(1,02,2,2) & 0,08 \\ \text { Não, não necessita } & 154 & 68 & (44) & \text { Ref. } & & \text { Ref. } & \end{array}$

RI: razão de incidência de quedas nos últimos 6 meses.

* Ajustado por sexo, idade e uso de medicamentos.

Dos participantes que faziam uso de álcool, 162 idosos relataram não fazer uso de álcool, e apresentaram incidência de quedas de(54\%) .

Quanto ao uso de óculos, 96 indivíduos relataram utilizarem óculos com melhora total e apresentaram incidência de quedas de (45\%).

Houve associação estatística em relação à fraqueza muscular e incidência de quedas ( $73 \%$ )e um valor de $\mathrm{p}<, 01$.

Dos 135 participantes com largura dos passos pequena, apresentaram uma incidência de quedas de (56\%). Em relação à simetria da marcha observou-se incidência de quedas de (59\%), e somente 45 idosos apresentaram problemas nos pés, e uma incidência de quedas de $(62 \%)$.

Foi observada associação estatística também, em relação ao uso de aparelho de audição e incidência de quedas (75\%) e apresentaram um valor de p de 0,02, e dos 30 idosos que não usavam aparelho de audição e relataram que necessitariam, apresentaram incidência de quedas de $(77 \%)$ e um valor de $\mathrm{p}<.01$.

Vários estudos sugerem que a fraqueza muscular relacionada com a idade afeta preferencialmente as extremidades inferiores (AMATUZZI et al., 2004; REBELATTO, MORELLI, 2004), comprometendo diretamente o seu desempenho muscular, que é crucial para caminhar, manter o equilíbrio, subir escadas, levantar e mover objetos, levantar-se da cadeira ou da cama ou do chão, limpar a casa, banhar-se ou vestir-se, que são as primeiras atividades afetadas com a sarcopenia na senilidade (DAVINI, NUNES, 2003; VREEDE et al., 2004; HENWOOD, TAAFFE, 2005). 
Moreland et al. (2004), realizaram uma metanálise com 13 estudos sobre quedas em idosos e notaram que a fraqueza muscular constituía um fator de risco para quedas em idosos. A função física envolve os três aspectos como a força muscular, a marcha e o equilíbrio, é amplamente reconhecida como componente fundamental para a qualidade de vida e possibilita o maior indicador aceito universalmente como estado de saúde em idosos, sendo que esta manutenção é a maior meta para geriatras e gerontólogos .

Ferrucci et al. (2004) enfatizam que é de grande importância melhorar o rastreamento de idosos com riscos de sofrerem incapacidades, para que estes possam aproveitar, em tempo oportuno e de forma orientada, os benefícios dos programas de intervenção na prevenção das incapacidades ( GURALNIK et al., 2000).

Um estudo realizado por Zanardiniet (2007), pesquisou oito idosos com queixa de tontura, na faixa etária de 63 a 82 anos, três do sexo masculino e cinco do sexo feminino. Realizaram-se os seguintes procedimentos: anamnese, inspeção otológica, avaliação vestibular por meio da vectoeletronistagmografia (VENG), aplicação do questionário DHI e dos exercícios de RV de Cawthorne e Cooksey. Houve melhora significativa na avaliação dos aspectos físico, funcional e emocional após aplicação dos exercícios de RV. Os autores concluíram que a ocorrência de alterações auditivas e vestibulares na população geriátrica justifica a realização sistemática da avaliação otoneurológica. $\mathrm{O}$ sucesso do tratamento da reabilitação labiríntica necessita da cooperação do paciente e de sua participação de forma ativa, causando um efeito psicológico positivo com a recuperação da segurança física e psíquica e conseqüente melhora da qualidade de vida. 
Tabela 11 - Razão de incidência de quedas nos idosos nos últimos 6 meses,ajustado por sexo, idade e uso de medicamentos. Catanduva, 2008.

\begin{tabular}{|c|c|c|c|c|}
\hline $\begin{array}{l}\text { Incidência } \\
\text { de quedas }\end{array}$ & RI & p & & $\mathbf{p}$ \\
\hline n $\quad(\%)$ & & & (IC 95\%) & \\
\hline
\end{tabular}

Escores do MEEM

$\begin{array}{lccccccc}5 \text { a } 20 & 48 & 30 & (63) & 1,5 & 0,05 & 1,1(0,91,4)^{*} & 0,41 \\ 21 \text { a } 30 & 152 & 72 & (47) & \text { Ref. } & \text { Ref. } & \end{array}$

Teste de equilíbrio

$\begin{array}{lccccccc}\text { Até } 6 & 57 & 41 & (72) & 1,7 & <, 01 & 1,1(1,01,2)^{*} & 0,08 \\ \text { Mais de } 6 & 143 & 61 & (43) & \text { Ref. } & \text { Ref. } & \end{array}$

Marcha

$\begin{array}{ccccccccc}0 & 8 & 8 & (100) & - & & - & \\ 1 & 38 & 21 & (55) & 2,2 & 0,02 & 1,8(0,93,6)^{*} & 0,12 \\ 2 & 51 & 29 & (57) & 2,3 & 0,01 & 1,8(0,93,7)^{*} & 0,08 \\ 3 & 71 & 36 & (51) & 2,0 & 0,03 & 1,8(0,93,4) * & 0,10 \\ 4 & 32 & 8 & (25) & \text { Ref. } & \text { Ref. } & \end{array}$

RI: razão de incidência de quedas nos últimos 6 meses.

* Ajustado por sexo, idade e uso de medicamentos.

Observou-se que houve associação estatística na Tabela 11, em relação aos escores do MEEM 48 idosos obtiveram um escores de 5 a 20, uma incidência de quedas de (63\%) e um valor de $\mathrm{p}$ de 0,05 .

Quanto ao teste do equilíbrio 57 idosos tiveram pontuação até 6 na escala de avaliação de desempenho físico de membros inferiores, Short Physical Performance Battery (SPPB) Guralnik (1994), e um valor de $\mathrm{p}$ significante ( $\mathrm{p}<, 01)$, em relação a marcha dos indivíduos que obtiveram de 1,2 a 3 pontos também apresentaram o valor de $\mathrm{p}$ significante $(\mathrm{p}<0,05)$. 
Guralnik e Winograd (1994), verificaram que existe um declínio evidente do escore na SPPB com o avanço da idade, ao estudarem uma amostra de 5.000 idosos acima de 71 anos, moradores na comunidade. Os idosos de 75-79 anos pontuaram 0,47 pontos a menos do que aqueles 73 com idade de 71-74 anos. Aqueles com 90 anos ou mais pontuaram 2,11 pontos também a menos, quando comparados com este mesmo grupo (71-74 anos).

Nakano (2007), demonstrou que, apesar da baixa correlação entre os domínios força versus equilíbrio, ao correlacioná-los com o domínio marcha, constatando forte magnitude. Também a correlação de cada domínio isoladamente versus o escore total da SPPB apresentou forte magnitude para todos os domínios, mas destacou que, para o domínio relacionado à marcha, houve maior valor.

Em outro estudo interessante com idosas mexicanas, com idades entre 65 e 99 anos, avaliaram separadamente cada domínio subseqüente, segundo o escore da marcha do SPPB (1, 2 e 3 pontos), que apresentaram como resultados: 5,4; 4.3 e 3,6 com maior possibilidade de desenvolver incapacidades, quando em comparação com o escore 4 (OSTIR et al.,1998). Entretanto, no domínio força ocorreu correlação significativa, verificando-se que o teste de equilíbrio isolado não prediz incapacidade.

Em uma pesquisa realizada por Rolland et al. (2006) foi demonstrado que o domínio marcha, quando avaliado isoladamente é forte preditor para a mortalidade. Em outro estudo realizado por Estefani (2007), pesquisando 96 idosos com relação ao déficit visual, desempenho físico de membros inferiores (Short Performance Battery SPPB), independência funcional (Medida de Independência Funcional MIF), medo de quedas (sim/não), auto-eficácia para quedas (Medida de Auto-eficácia para quedas) e sintomas depressivos (Epidemiologic Scale - Depression CES-D), com o objetivo analisar o comportamento das variáveis sociodemográficas, clínicas, físicas, funcional e psicológica em idosos atendidos em um Ambulatório de Geriatria.

Identificando o perfil destes idosos quanto à ocorrência de quedas, verificou-se que as variáveis que mais contribuíram para a formação dos agrupamentos foram a independência funcional, auto-eficácia para quedas, desempenho físico de membros inferiores, idade e gênero. Mulheres com idade média de73 anos, com baixos valores da MIF e do SPPB, e com menor auto-eficácia apresentaram maior risco para quedas $(\mathrm{OR}=7,04)$. Os resultados apontam uma relação entre desempenho físico, independência funcional e auto-eficácia. 
Vale ressaltar a importância de intervenções e prevenção de quedas, considerando simultaneamente os domínios físico, funcional e psicológico do idoso. 
CONCLUSÕES 


\section{CONCLUSÕES}

O estudo sobre Alteração do Equilíbrio e Marcha e Ocorrência de Quedas realizado na Associação dos Aposentados e Pensionistas de Catanduva e Região foi realizado com uma população de 200 idosos, permitiu as seguintes conclusões:

- As quedas ocorreram em 102 idosos entrevistados, sendo mais freqüentes no sexo feminino $(56 \%)$.

- Conclui-se que a ocorrência de quedas está associada a fraqueza muscular e a atividade física .

- Verificou-se que a audição também está associada a ocorrência de quedas, a partir dos dados coletados no uso de óculos e aparelho de audição, não foi observado diferença entre os sexos.

- Evidenciou-se que as quedas estão associadas ao déficit cognitivo (63\%).

- Notou-se que as quedas estão associadas ao equilíbrio e a marcha, sendo que os idosos que caíram obtiveram escores menores na escala de Avaliação de desempenho físico de membros inferiores (SPPB).

- As quedas apareceram associadas ao uso de medicamentos.

- Conclui-se também, que as quedas foram mais frequientes fora dos domicílios (62\%).

- Dos idosos que sofreram quedas, $61 \%$ relataram que caíram por alterações externas.

- Com base neste estudo conclui-se de maneira geral que as quedas trazem consequiências drásticas à população idosa e que a prevenção é o principal fator determinante para evitar complicações futuras.

É necessário ressaltar a importância de uma equipe multidisciplinar, para melhorar a qualidade vida do idoso proporcionando melhor dependência funcional. 
CONSIDERAÇÕES FINAIS

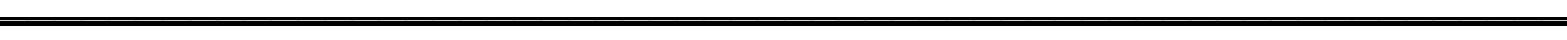




\section{CONSIDERAÇÕES FINAIS}

O presente estudo teve várias limitações, tais como: o agendamento dos idosos para a entrevista, foi realizado por meio de sorteio do nome e logo em seguida a pesquisadora entrou em contato com os mesmos por telefone, mas haviam idosos que mudaram de residência, ou que residiam em outro município ou mesmo que faleceram.

Esta pesquisa nos trouxe muita satisfação, pois a maioria dos idosos nunca tinham participado de nenhum tipo de pesquisa e demonstravam entusiasmo em realiza-la, no final da pesquisa a maioria dos entrevistados questionavam, se já tinha terminado e demonstravam ou relatavam outras habilidades que realizavam, tais como: corrida, agachamento, historias do cotidiano ou testes de memórias que faziam diariamente e alguns questionamentos sobre a pesquisa. Como pesquisadora me sinto muito lisonjeada, pois consegui atingir os objetivos propostos, na presente pesquisa. 


\section{REFERÊNCIAS BIBLIOGRÁFICAS}




\section{REFERÊNCIAS BIBLIOGRÁFICAS}

ABREU, F. M. C.; LOPES, R. Q.; GRABRIEL, C.; BARBOSA, W.; DANTAS, E.; MARTIN, H. Analise quantitativa da marcha no idoso institucionalizado. Fisioter. Bras. v. 4, n. 2, p. 92-95, mar./abr. 2003.

AMATUZZI, M. M., AlBUQUERQUE, R. F. M., AMATUZZA, M. L., SASAKI, S. U. O tratamento cirúrgico é imperativo na lesão do ligamento cruzado anterior? Há lugar para o tratamento conservador? Revista Brasileira de Ortopedia. Agosto, 2007.

BARAÚNA, M.; BARBOSA S. R. M.; CANTO R. S. T.; SILVA R. A. V.; SILVA C. D.C.; BARAÚNA K. M. P. Estudo do equilíbrio estático de idosos e sua correlação com quedas. Fisioterapia Brasil, v.5, n.2, p.136-141, mar/abr. 2004.

BARAFF. L .J.; DELlA, P. R.; WILLIANS, N. et al. Practice guideline for the ED Management of falls in community - dwelling elderly persons. .Ann Emerg Med. V. 30, p.480-492, 1997.

BARDEL, A.; WALLANDER, M. S.; VÄRDSUDD, K. Reported current use of prescription drugs and some of its determinants among 35 to 65-year-old women in mid-Sweden: A population-based study. Journal of Clinical Epidemiology, v.53, p. 637-643, 2000.

BITTAR, R. S. M.; PEDALINI M. E B.; BOTTINO M. A.; FORMIGONI L. G. Síndrome do desequilíbrio no idoso. Pró-fono. Revista de Atualização Científica, São Paulo, v. 14, n. 1, p. 119-128, 2002.

BRANDT, A. C.; RICIERI, D. V.; GRIESBACH, L. E. S.Repercussões respiratórias da aplicação da técnica de isostretching em indivíduos sadios. Fisioterapia Brasil, v. 2, p. 103110, mar/abr. 2004. 
BRUCKI, S. M. D.; NITRINI, R.; CARAMELLI, P.; BERTOLUCCI, P. H. F.; OKAMOTO, I. H. Sugestões para o uso do mini-exame do estudo mental no Brasil. Arquivo de Neuropsiquiatria, São Paulo, v. 61, n. 3, p. 777-781, set. 2003.

BERTOLUCCI, P. H. F.; BRUCKI, S. M. D.; CAMPACCI, S. R.; JULIANO, YARA. O mini-exame do estado mental em uma população geral: impacto da escolaridade. v. 1, n. 7, p. 52-61, mar. 1994.

BIRGE, S. J. Can falls and hip fracture be prevented in frail older adults? J Am Geriatr Soc. v. 47 , p. $1265-1266,1999$.

CAPODIECI, S. A idade dos sentimentos: amor e sexualidade após os sessenta anos. ,Edusc. Bauru, SP, p. 175, 2000.

CARAMELLI, P.; NITRINI, R. Como avaliar de forma breve e objetiva o estado mental de um paciente?Rev. Assoc. Med. Bras. v.46 n.4 São Paulo,oct./dec. 2000.

CARLOS, A.; REYES, O.; SOHAM, A. 1. S.; KYRIAKOS, S. M. Falls among elderly persons in Latin America and the Caribbean and among elderly Mexican-Americans. Rev. Panam Salud Publica, Washington, v. 17, p. 5-6, maio/jun. 2005.

CARVALHO, A. M.; COUTINHO, E.S.F.Demência como fator de risco para fraturas graves em idosos. Revista de saúde pública, v.36, n.4, p.448-454, Abril, 2002.

COUTO, F. B. D.; PERRACINI, M. R. Perfil de idosos ativos participantes de um grupo de terceira idade do município de itu que sofreram quedas. 2006, 117 f. Dissertação ( Mestrado em Educação) - Faculdade de Educação, Universidade Estadual de Campinas, Campinas, 2006.

COlledGE, N. R.; WILSON, J. A.; MACINTYRE, C. C.; MACLENNAN, W. J. The prevalence and characteristics of dizziness in an elderly community. Age Ageing .v. 23, p.11720.1994. 
COELHO, J. M. F..; MARCOPITO, L. F. CASTELO, A. Perfil de utilização de medicamentos por idosos em área urbana do nordeste do Brasil. Ver. Saúde Pública, v.38, p.557-64, 2004.

COUTINHO, E. S. F.; SILVA, S. D. Uso de medicamentos como fator de risco para fratura grave decorrente de quedas em idosos. Caderno Saúde Pública, rio de Janeiro, v.18, n.5, p. 1359-1366, Set/Outubro, 2002.

DAVINI, R; NUNES, C. V. Alterações no sistema neuromuscular decorrentes do envelhecimento e o papel do exercício físico na manutenção da forca muscular em individuos idosos. Rev. Bras. Fisioter; v. 7, n. 3, p. 201-207, set.-dez. 2003.

ENSRUD, K. E.; NEVITT, M. C.; YUNIS, C.; HUllEY, S. B.; GRIMM, R. H.; CUMMINGS, S. R. Postural hypotension and postural dizziness in elderly women. Arch Intern Med, v. 152, p. 1058-1064, 1992.

ESTEFANI, G. A. E. Perfil de idosos atendidos em ambulatório de geriatria segundo a ocorrência de quedas. 2007. 118 f Dissertação (Mestrado em Gerontologia) - Faculdade de Educação, Universidade de Campinas, Campinas, 2007.

FABRÍCIO, S. . C.; RODRIGUES, R. A. P. et al. Causas e consequiências de quedas de idosos atendidos em hospital público. Revista de Saúde Pública, v.38, n.1, p. 93-99, 2004.

FARIA, J. C.; MACHALA, C. C.; DIAS, R. C.; DIAS, J. M. D. Importância do treinamento de força na reabilitação da função muscular, equilíbrio e mobilidade de idosos. ACTA Fisiátrica, v. 10, n. 3, p.133-137, 2003.

FERREIRA, J. V. C. Os muitos idosos do município de São Paulo-SP. 2006. 32 f. Dissertação (Mestrado em Saúde Publica) - Faculdade de São Paulo, Universidade de saúde Pública, São Paulo, 2006. 
FERRUCCI, L. ;GURALNIK, J. M.; STEPHANIE, S. S.; LINDA P. FRIED, L. P.; GORDON, B. ; CUTLER JR.; JEREMY, D.; W. Designing Randomized, Controlled Trials Aimed at Preventing or Delaying Functional Decline and Disability in Frail, Older Persons: A Consensus Report. Journal of the American Geriatrics Society, v.52 n.4, p. 625 - 634, 2004.

FILHO, E. T. C.; NETTO. M. P. Quedas. In. PASCHOAL, S. M. P.; LIMA, E. M. GeriatriaFundamentos, clínica e terapêutica. 2. ed. São Paulo: Atheneu, 2005. cap. 53. p. 581-590.

FOLSTEIN, M. F.; FOLSTEIN, S. E.; MCHUCH, P. R. Mini-mental state: a pratical method for grading the cognitive state of patients for clinician. Jounal psychiatric, New York, v. 12, p. 189-198, 1975.

FLORES, L. M.; MENGUE, S. S. Uso de medicamentos por idosos na região sul do Brasil.v. 39,p.924-29, 2005.

FREITAS, E. V.; PY, L.; CANÇADO, F. A. X.; DOLL, J. GORZONI, M. L. Distúrbio da postura, marcha e quedas. In. JÚNIOR, C. M. P.; HELCKMAN, M. F. Tratado de Geriatria e Gerontologia. 2. ed. Rio de Janeiro: Guanabara Koogan. cap. 98. p. 950-961. 2006.

FULLER, G.F. Falls in the elderly. Am Fam Physician, v.61, p.2159-2174, 2000.

GANANÇA, F. F.; GAZZOLA, J. M.; PERRACINI, M. A.; GANANÇA, M. M. Circunstâncias e consequiências de quedas em idosos com vestibulopatia crônica. Octo. Otorrinolaringol, São Paulo, v.72, n.3, maio/jun. 2006.

GAZZOLA, J. M.; PERRACINI, M. R.; GANANÇA, M. M.; GANANÇA, F. F. Fatores associados ao equilíbrio funcional em idosos com disfunção vestibular crônica Rev. Bras. Otorrinolaringol. vol.72 no.5 São Paulo sept./oct. 2006.

GANANÇA, M. M.; CAOVILlA, H. H. Desequilíbrio e reequilíbrio. In: Ganança, M. M. Vertigem tem cura? São Paulo: Lemos Editorial, p.13-19, 1998. 
GEIB, L. T. C.; CATALDO, N, A.; WAINBERG, R.; NUNES, M. L. Sono e Envelhecimento. Revista de psiquiatria, Rio Grande do Sul, v. 25, n. 3, p. 453-465, set/dez, 2003.

GONZÁLEZ, G., MARIN, P.P. et al. Características de las caídas em el adulto mayor que vive em la comunidad. Revista Médica do Chile, v.129, n.9, p. 1021-30, 2001.

GOUlART, F.; CHAVES, C. M.; Márcia, L. D.; CHAGAS; VALlONE; CARVALHO, J. A.; SAIKI, K. R. O movimento de passar de sentado para de pé em idosos. Implicações Para o Treinamento Funcional. ACTA Fisiátrica, v.10, n.3, p.138-143, 2003.

GUCCIONE, A. A. Fisioterapia geriátrica. 2 ed., Rio de janeiro: Guanabara Koogan, 2002.

39- GURALNIK, J. M. et. al. A short physical performance battery assessing lower extremity function: association with self-reported disability and prediction of mortality and nursing home admission. J Gerontol. Washington, v. 49, n. 2, p. 85-94, mar. 1994.

GURALNIK, J. .M.; FERRUCI, L.; PIEPER, C.F.; LEVELLE, S.G.; MARKIDES, K.S.; OSTIR, G.V. Lower extremity function and subsequent disability: consistency across studies, predictive models, and value of gait speed alone compared with the studies, predictive models, and value of gait speed alone compared with the Short Physical Performance Battery. J.Gerontol. Med. Sci. v 55, n.4, 221-31, 2000.

GURALNIK, J. M, WINOGRAD, C.H. Physical performance measures in the assessment of older persons. Aging Clin Exp Res., v. 6, n.5, p. 303-305, 1994.

GRAAFMERS, W.C.; OSMS, M.E. et al. Falls in the elderly: a prospective study of risk factors and risk profile. American Journal of Epidemiology, v.143, n.11, p.1129-36, 1993.

GRATÃO, A. C. M. et al. Avaliação prospectiva do idoso demenciado que teve queda. R enferm UERJ, v. 11, n. 2, p.147-2, 2003. 
HAIN. T. C.; RAMASWAMY, T. S.; HILLMAN, M. A. Anatomia e fisiologia do sistema vestibular normal. In: HERDMAN, S. J. Reabilitação vestibular. 2. ed. São Paulo: Manole, p. 3-24, 2002.

HATZITAKI, V.; AMIRIDS, I. G.; ARABATZI, F. Aging effects on postural responses to self imposed balance perturbation. Gait \& Posture, Amsterdam, 2005.

HENRIQUES, G. R. P.; PEREIRA, J. S.; SILVA, M. A. G. A interferência da imobilização intra-articular na amplitude de coxo femural em idosos. Fisioterapia Brasil, São Paulo, v.5, n.1, p.22-28, jan/ fev. 2004.

HENWOOD, T. R.; TAAFFE, D. R. Improved Physical Performance in Older Adults Undertaking a Short-Term Programme of High-Velocity Resistance Training. . Rev. Gerontology..v.51,n.2,p.108-115,2005.

IBGE - INSTITUTO BRASILEIRO DE GEOGRAFIA - Disponível em. http://www.ibge.gov.br . Acesso em: set. 2008.

ISHIZUKA, M. A.; MUTERELI, E. G.;YAMAGUCHI, A. M.; JACOB, W. F. Falls by elders with moderate levels of movement functiolity. Clinics, São Paulo, v. 60, n. 1, p. 41-46, October. 2004.

JÚNIOR, C. M. P.; HECKMANN, M. Distúrbios da postura, marcha e quedas. In: FREITA E. V. et al.Tratado de Geriatria e Gerontologia, Rio de Janeiro: Guanabara Koogan, p. 624-634, 2002.

JURKIEWICZ, A.L.; ZEIGELBOIM, B. S.; MANGABEIRA-ALBERNAZ, P. L. Alterações vestibulares em processos infecciosos do sistema nervoso central. Dist. Comun., São Paulo, v. 14, n. 1, p. 27-48, dez. 2002.

LAFER, B.; ALMEIDA, O. P.; JR, F. R.; MIGUEL, C. E. Características clinicas, fatores de risco e curso da depressão em idosos In. BLAY, S. L. Depressão no ciclo da vida. Porto Alegre: Artmed, cap. 4, p.45-54, 2000. 
LAKS, J.; BATISTA, E. M. R.; LIMA G. E. R. et al. O mini exame do estado mental em idosos de uma comunidade: dados parciais de Santo Antônio de Pádua, RJ. Arq. NeuroPsiquiatr, vol.61, no.3B, p.782-785, sept. 2003.

LOJUDICE, D. C. Quedas de idosos institucionalizados: ocorrência e fatores associados. 2005. 90f. Dissertação (Mestrado em Saúde na Comunidade) - Faculdade de Medicina de Ribeirão Preto, Universidade de São Paulo, Ribeirão Preto, 2005.

MADUREIRA, M. M. Efetividade de um programa de treino de equilíbrio no estado funcional e na frequiência de quedas em mulheres idosas com osteoporose: estudo randomizado e controlado. 2007. f. 96. Dissertação ( Mestrado em Reumatologia) - Faculdade de medicina , São Paulo, 2007.

MANTOVANI, E. P. Saúde física, indicadores antropométricos, desempenho físico e bem-estar subjetivo em idosos atendidos no ambulatório de geriatria do HC/UNICAMP. 2007. f. 114. Dissertação ( Mestrado) Faculdade de Educação Física, Universidade Estadual de Campinas, Campinas, SP, 2007.

MEIRELLES ,G. V. Prevalência de dilatação da aorta abdominal em coronariopatas idosos. 2003. 99 f. Dissertação (Mestrado em Educação) - Universidade de Campinas, Campinas, 2003.

MERCK ( home page da internet), the Merck manual of Geriatrics.FALLS; Section 2, Chapter 20. (acesso em 31 de agosto de 2008). Disponivel em: http:// www.merck.com/mrkshared/mmg/sec2/ch20/ch20a.jsp

MILLER, D. K.; Wolinsky, F.D.; Andresen, E. M. ;Malmstrom, T. K.; Miller, J. P. Adverse outcomes and correlates of change in the Short Physical Performance Battery over 36 months in the African American health project. Revista: J Gerontol A Biol Sci Med Sci (The journals 
of gerontology. Series A, Biological sciences and medical sciences), v.63, ed.5, p.487-94, May, 2008.

MITSUCHI; BERGAMINI, M. L.; JAMUSSI, GRACIA, S.; MARTINS; FACHI, E.Intervenções fisioterapêuticas e podológicas nos pés de idosos podem proporcionar marcha mais segura: Saúde do idoso: A Arte de Cuidar. Fisio Brasil, Rio de Janeiro, v. 6, n.1, p. 3640, jan /fev. 2004.

MONCUR, C. A.; Fisioterapia geriátrica.. In: GUCCIONE, A. A. Postura no idosos. 2 ed. Rio de Janeiro: Guanabana Koogan, 251-264 p.2002.

MOTA, P. H. M.; FRANCO, E. S., Pinto, E. S. M., Arieta, A. M. Estudo do equilíbrio no idoso por meio da electronistagmografia. Acta Awho.São Paulo, v. 21, n.3, p. 1-12, jun-dez., 2002.

MOREland, J. D., RICHARDSON, J. A., GOLDSMITH, C. H., ClASE, C. M. Muscle weakness and falls in older adults: a systematic review and meta-analysis. J Am Geriatr Soc, v. 52, n. 7, p.1121-1129, 2004.

MOSEGUI, G. B. G., ROZENFELD, S., VERAS, R. P., VIANNA, C. M. M. Avaliação da qualidade do uso de medicamentos em idosos. Rev. Saúde Pública. V..33, n..5, outubro 1999.

NAKANO, M. M. Versão Brasileira da short physical performance battery -sppb: adaptação cultural e estudo da confiabilidade-2007. 163 f. Dissertação ( Mestrado em Educação) Faculdade de Educação, Universidade Estadual de Campinas, Campinas, 2007.

NELDER, J.A.; WEDDERBURN, R.W.M. Generalized linear models. Journal of the Royal Statistical Society A, v.135, p. 370 - 384, 1972.

OLIVEIRA, D. L. C.; GORETTI, L. C.; PEREIRA, L. S. M. Desempenho de idosos institucionalizados com alterações cognitivas em atividades de vida diária e mobilidade: estudo piloto. Octo Fisioterapia, São Carlos, v.10, n.1, 2006. 
OLIVEIRA, R. C. estudo da ocorrência de quedas e seus fatores de risco em idosos não institucionalizados na cidade de Batatais - SP. 2002. 91 f. Dissertação (Mestrado em medicina Preventiva) - Faculdade de Medicina, Universidade de São Paulo, Ribeirão Preto, 2002.

OSTIR, G.V.; MARKIDES, K.S.; BLACK, S.A.; GOODWIN, J.S. Lower body functioning as a predictor of subsequent disability among older Mexican Americans. Journal of Gerontology: Medical Sciens. V. 53 a , n.6, p. M49-M495, 1998.

PAPALÉO N. M. Gerontologia: A velhice e o envelhecimento em visão globalizada. São Paulo: Atheneu, 2002, p.230, 2002.

PAULA, J..A. M. Avaliação do idoso : capacidade funcional, independência e sua relação com outros indicadores de saúde. 2007. 131f. Tese ( Doutorado em Educação, Sociedade Política e Cultura)- Faculdade de Educação, Universidade Estadual de Campinas, Campinas, 2007.

PFALTZ, C.R.; PROBST, R.; ALLUM, J..M..J. Impairment of auditory and vestibular function in the elderly. In: Dall JLC, Ermini M, Herrling PL. Adaptations in aging. San Diego: Academic Press,p. 131-48, 1999.

PEREIRA, S. R. M.; BUKSMAN, S. PERRACINI, M.; et. al..Sociedade brasileira de geriatria e gerontologia. Projeto diretrizes.Quedas em Idosos. AMB/CFM, p.1-9,jun., 2006.

PEREIRA, R. J.; COTTA, R. M. M. ; FRANCESCINI, S. C. C; RIBEIRO, R. C. L; SAMPAIO, R. F.; PRIOR,I S. E.; CECON, P. R. Contribuição dos domínios físico, social, psicológico e ambiental para a qualidade de vida global de idosos. Ver. Psiquiatria. Rio Gd. Sul, v. 28, n. 1, jan./abr. 2006.

PEREIRA, M. G. Epidemiologiateórica e prática. Rio de janeiro: Guanabara Koogan, p. 271$274,1995$. 
PERRACINI, R. M. Fatores associados à quedas em uma coorte de idosos residentes no município de São Paulo. 2000. 242f. Tese (Doutorado em Ciências) - Escola Paulista de Medicina, Universidade Federal de São Paulo, São Paulo, 2000.

PÉRENNOU, D.; DECAVEL, P.; MANCHOUNDIA, P.; PENVEN, Y.; MOUREY, F.; LAUNAY, F.; PfFITZENMEYER; CASILLAS, J. M. Evaluation of balance in neurologic and geriatric disorders. Annales de Réadaptation et de Médice Physique, v. 48, n. 6, p. 317-335, jul. 2005.

PROVINCE, M. A.; HADLEY, E. C.; HORNBROOK, M. C.; LIPSITZ, L. A.; MILLER, J. P.; MULRON, C.D.; ORY. M. G.; SATTIN, R. W.; TINETTI, M.E.; WOLF, S.L. The effect of exercise on falls in the elderly patients - a preplanned meta-analysis of the FICSIT trials. JAMA, v.17, n. 273, p. 1341-1347, 1995.

RAMOS, L.R., ROSA, T.E.C. et al. Perfil do idoso em área metropolitana na região sudeste do Brasil: resultados de inquérito domiciliar. Revista de Saúde Pública, v. 27, n.2, p. 87-94, 1996.

REIS, L. A.; MASCARENHAS, C. H. M.; COSTA, A. N.; LESSA, R. S. Estudo das condições de saúde de idosos em tratamento no setor de neurogeriatria da clínica escola de fisioterapia da Universidade Estadual do Sudoeste da Bahia.Revista Baiana de Saúde Pública. v.31, n.2, p.322-330 jul./dez. 2007.

REBELATTO, J. R.; MORELLI, J. G. S. S. A pratica da assistência ao idoso. Fisioterapia Geriátrica. São Paulo, ed. Manole, p. 455, 2004.

RIBEIRO, A. S. B.; PEREIRA, J. S. A melhora da capacidade do alcance funcional em mulheres idosas após os exercícios de Cawthorne e Cooksey. Fisioterapia Brasil, São Paulo, v. 5, n. 2, mar/abr. 2004. 
ROBBINS, A. S.; RUBENSTEIN, L. Z.; LOSEPHSON, K. R.; SCHULMAN, B. L.; OSTERWEIL, D.; FINE, G.Predictors of fallz among elderly people. Results of two population based studies. Archives International Medicine, v. 149, p.1628-1633, 1989.

ROCHA, C.;GOBBI, I.;MARIANA MAZZARINO, M.;SAMANTA KRABBE, S.;SILVIA VIRGINIA COUTINHO AREOSA, S. V. C. Como mulheres viúvas de terceira idade encaram a perda do companheiro. RBCEH - Revista Brasileira de Ciências do Envelhecimento Humano, Passo Fundo, p. 65-73, jul./dez, 2005.

ROLLAND, Y.; LAUWERS-CANCES, V.; CESARI, M; VELLAS, B.; PAHOR, M.; GRADJEAN, H. Physical performance measures as predictors of mortality in a cohort of community-dwelling older French women. European Journal of Epidemiology, v.21, p.113$122,2006$.

ROSA, G. M. M.; SOUZA, W. C.; PINTO, L. D.P.; GARBAN, G. A.; SERAFIM, A. D.; FARIA, E. T. B. Análise da influencia do estresse no equilíbrio postural. Fisioterapia Brasil, v.5, n.10, p. 50-55, jan/fev. 2004.

RUBENSTEIN, E.; JOSEPHSON. The epidemiology of falls and syncope. Clin geriatr, med. V.18, p.141-158, 2002.

RUSSO, G. A. H. F. A prevenção da enfermidade e a promoção da saúde: o envelhecimento com êxito. Atual Geriatr, v.15,p. 30-34, 1998.

RUWER S. L.; ROSSI A. G.; SIMON L. F. Balance in the elderly. Rev. Bras. Otorrinolaringol., São Paulo, v. 71, n. 3, may/jun. 2005.

SIQUEIRA, F. U. ;FACCHINI, L. A.; PICCINI, R. X. ; TOMASI, E.; THUMÉ, E.; SILVEIRA, D. S.; VIEIRA, V.; HALLAL, P. C. Prevalência de quedas em idosos e fatores associados. Ver. Saúde Publica, v. 41, n. 5, p. 749-756, 2007. 
SIGNORETTI, D.C.O. M. Capacidade funcional, condições de saúde, sintomas depressivos e bem-estar subjetivo dos idosos atendidos no ambulatório de geriatria do hospital das clínicas da HC-UNICAMP-SP - SP. 2007. 70 f. Dissertação (Mestrado em Gerontologia)- Faculdade de Educação, Universidade Estadual de Campinas, Campinas, 2007.

SILVEIRA, S. R.; TAGUCHI, C. K.; GANANÇA, F. F. Análise comparativa de duas linhas de tratamento para pacientes portadores de síndromes vestibulares periféricas com idade superior a sessenta anos. Acta Awho. São Paulo, v. 21, n. 1, p. 1-13, jan-mar., 2002.

SIMOCELI, L.; BITTAR, R. M. S.; BOTTINO, M. A.; Bento, R.F.Perfil diagnóstico do idoso portador de desequilíbrio corporal: resultados preliminares Rev. Bras. Otorrinolaringol. vol.69 no.6 São Paulo Nov./Dec. 2003.

SCHROETER, G. TROMBETTA, T. FAGGIANI, F. T. GOULART, P. V. CREUTZBERG, M. VIEGAS, K. SOUZA, A. C. CARLI, G. A. MORRONE, G. A. Terapia anti-hipertensiva utilizada por pacientes idosos de Porto Alegre/RS, Brasil. Scientia Medica, Porto Alegre, v. 17, n. 1, p. 14-19, jan./mar. 2007.

SKOV T, DEDDENS J, PETERSEN MR, ENDAHL L. Prevalence proportion ratios: estimation and hypothesis testing. International Journal of Epidemiology, v.27, p. 91-95, 1998.

STEADMAN, J.; DONALDSON, N.; KALRA, L.. A randomized controlled trial of an enhaced balance training program to improve mobility and reduce falls in elderly patients. American Geriatrics Society, v. 51, n. 6, p. 847-852, 2003.

TELLES, A. C. M. Prevalência, incidência, fatores preditivos e impacto das quedas entre as pessoas idosas residentes no município de São Paulo- uma visão longitudinal. 2008. f.74. Dissertação (Mestrado). Escola de Enfermagem, Universidade de São Paulo, 2008.

TILVIS, R.J.; HAKULA, S. M.; VALVANNE, J.; ERKINJUNTTI, T. Postural hypotension and dizziness in a general aged population: a four-year follow-up of the Helsinki Aging Study. J Am Geriatr Soc, v.44, p. 809-814, 1996. 
TINETTI, M. E.; WILLIAMS, C. S.; GILL ,T. M. Dizziness among older adults: a possible geriatric syndrome. Ann Intern Méd.v.7, n.5, p. 337-344, mar, 2000.

TINETTI, M. E.; BAKER, D.; MCAVAY, G., CLAUS, E.B.; GARRET, P., GOTTSCHALK, M.; KOCH, M.L.; TRAINOR, K.; HORWITZ, R. I.A multifactorial intervention to reduce the risk of falling among elderly people living in the community. Journal of Medicine, v.331, n.13, p.821-827, September, 1994.

VERAS, R. Em busca de uma assistência adequada à saúde do idoso. Revisão da Literatura e Aplicação de um Instrumento de Detecção Precoce e de Previsibilidade de Agravos. Rio de Janeiro, Cad. Saúde Pública, v.19, n.3, jun. 2003.

VREEDE, P. L; SAMSON, M. M.; VAN MEETEREN N. L. ; VAN DER BOM, J.G.; DUURSMA, S. A.; VERHAAR, H. J.Functional tasks exercise versus resistance exercise to improve daily function in older women: A feasibility study. Arch Phys Med Rehabil. v.85, n.12, p. 1952-1961, 2004.

WEINCHUCH, R.; KORPER, SP. ;HALDLEY, E. The prevalence of october oibrium and related disorders in older persons. Acta Otolaryngol, v.529, p. 108-110, 1997.

WHITNEY, S. L. Tratamento do idoso com disfunção vestibular. In: HERDMAN, S. J. Reabilitação vestibular. 2. ed. São Paulo: Manole. p. 505-528, 2002.

WISKTEN, D. L.; PERRIN, D.H.; HARTMAN, M.L.; GIECK, J. H.; WELTMAN A. The relationship between muscle andb alance performance as a function of age. Isokinetcs Exercise Science. v. 6, p. 125-32, 1996.

ZANARDINI, F. H.; ZEIGELBOIM, B. S. JURKIEWICZ, A. L.; MARQUES, J. M.; BASSETTO, J. M.Reabilitação vestibular em idosos com tontura. Pró-Fono R. Atual. Cient. v.19 n.2 Barueri, p. 17 abr./jun. 2007. 



\section{APÊEDICES}




\section{APÊNDICE A}

Faculdade de Medicina de Ribeirão Preto - Universidade de São Paulo Projeto de Pesquisa: “Alteração do Equilíbrio e Marcha em Idosos”. Termo de consentimento livre e esclarecido

( Conselho Nacional de Saúde, resolução 196/96)

$\mathrm{Eu}$ declaro que concordo e me proponho a participar da pesquisa"Alteração do equilíbrio e Marcha em Idosos". Tenho consciência que serei apenas entrevistado e avaliado pelo pesquisador responsável sobre condições de minha saúde física e mental. Entendo que meu bem estar físico, moral e social será plenamente respeitado, e que poderei desistir no momento em que desejar. Reconheço que serei avaliado em meu estado mental e social e que minha identidade será resguardada. Reconheço também, que estou contribuindo para o desenvolvimento científico em nível coletivo da terceira idade, e que receberei esclarecimentos adicionais consultando o pesquisador por telefone (17 35247978 e/ou 97737108), caso ache necessário a qualquer momento em que tiver dúvida, visto que minha participação encerra-se ao final da entrevista. Assim, consinto em participar do estudo respondendo ao questionário, e sendo avaliado, por livre vontade.

PARTICIPANTE DA PESQUISA

Pesquisador Responsável Thaise Lucena Silva

Data: 1 
Faculdade de Medicina de Ribeirão Preto - Universidade de São Paulo Projeto de Pesquisa: “Alteração do Equilíbrio e Marcha em Idosos". Termo de consentimento livre e esclarecido (Conselho Nacional de Saúde, resolução 196/96)

$\mathrm{Eu}$, portador do documento de identidade $\quad \mathrm{n}^{\mathbf{o}}$ responsável pelo idoso (a) autorizo que o mesmo(a) participe da pesquisa" Alteração do equilíbrio e Marcha em Idosos" Tenho consciência que o(a) mesmo(a)que será entrevistado e avaliado pelo pesquisador responsável sobre condições de sua saúde física e mental. Entendo que seu bem estar físico, moral e social será plenamente respeitado, e que o(a) mesmo(a) poderá desistir no momento em que desejar. Reconheço que será avaliado em meu estado mental e social e que sua identidade será resguardada. Reconheço também, que estaremos contribuindo para o desenvolvimento científico em nível coletivo da terceira idade, e que receberemos esclarecimentos adicionais consultando o pesquisador por telefone (17 35247978 e/ou 97737108), caso achemos necessário a qualquer momento em que tivermos dúvida, visto que sua participação encerra-se ao final da entrevista. Assim, consinto em participar do estudo respondendo ao questionário, e sendo avaliado, por livre vontade.

\section{PARTICIPANTE DA PESQUISA}

Pesquisador Responsável Thaise Lucena Silva

Data:

1




\title{
APÊNDICE B
}

\section{Questionário para coleta de dados}

\author{
.Identificação do Perfil do Idoso
}

1-Iniciais:

2-Sexo: ( )Masculino ( ) Feminino

3-Idade:

4-Escolaridade:

( )Analfabeto

( )Primário Incompleto( $1^{\circ}$ a $4^{\circ}$ série)

( )Primário completo

( )Ginásio incompleto( $5^{\circ}$ a $8^{\circ}$ série)

( )Ginásio completo

( )Colegial incompleto $\left(2^{\circ}\right.$ grau $)$

( ) Colegial Completo

( )Curso superior incompleto

( ) Curso superior completo

5- O senhor(a) mora sozinho?

( ) $\operatorname{sim}$

( ) não Especifique

6- O senhor (a) tem companheira (o)? 
( ) $\operatorname{Sim}$

( )Não

7-O Senhor(a) faz uso de Medicamentos:

( ) $\mathrm{Sim}$

( ) Não

8- Quem receitou o (os) remédio (os)?

Especifique

11- Nome do medicamento:

9-Número de Medicamentos:

10-O Senhor pratica algum esporte regularmente?

( ) Sim (Especifique: Qual quantas x por semana).

( ) Não

( ) NS

( ) NR

11-O Senhor(a) usa óculos?

( )Sim, com melhora Total

( )Sim, com melhora Parcial

( )Não, mas Necessitaria

( )Não, Não tem Necessidade

( ) NS

( ) NR

12-O Senhor(a) usa aparelho de audição?

( )Sim, com melhora Total 
( )Sim, com melhora Parcial

( )Não, mas Necessitaria

( )Não, Não tem Necessidade

( ) NS

( ) NR

13-O Senhor(a) apresenta algum problema nós pés?( Observar)

( ) Calosidades

( ) Feridas

( ) Unha encravada

( ) Hálux valgo

( ) Dedos em garra

( ) Não apresenta

( ) Outros: Quais:

14-O Senhor(a) sofreu alguma quedas nos últimos 6 meses?

( ) $\operatorname{Sim}$

( ) Não

15-Freqüência de quedas?

( )Sempre

( )As vezes

( )Raro

( )Nunca

16- O senhor(a) fuma?

( ) $\mathrm{Sim}$

( ) Não

17- O senhor(a) faz uso de bebida alcoólica?

( ) Sim 
( ) Não

18-O Senhor(a) fez uso de bebida alcoólica no dia da queda?

( ) $\operatorname{Sim}$

( ) Não

19-O Senhor (a) apresenta Fraqueza Muscular? (informação verbal)

( ) $\mathrm{Sim}$

( ) Não

( ) De vez Em quando

20-Largura do passo:

( ) Passos pequenos

( ) Passos largos

21-Simetria da Marcha: (Observar)

( ) Marcha oscilante

( ) Marcha claudicante

( ) Marcha de tesoura

( )Marcha simétrica

( )Marcha Assimétrica

22-A que o senhor(a) atribui a queda?

Especifique

Condições Extrínsecas

23-Qual foi o Local da Queda?

( )Banheiro

( )Quarto

( )Sala 
( ) Cozinha

( )Varanda

( )Outro(Fora da casa)

Especifique:

( ) Ns

( ) NR

24-Qual o Piso encontrado no local da queda?

( ) Liso

( ) áspero

( ) Outro

Especifique;

( ) NS

( ) NR

25-Qual o estado do piso no local da queda?

( ) Seco

( ) Molhado

( ) Taco solto

( ) Encerado

( ) Buraco no Chão

( ) Outro

Especifique:

( ) Ns

( ) NR

26-Qual o tipo de calçado usado na ocorrência da queda?

( ) Sapato fechado

( ) Chinelo

( ) Sandália

( ) Outro 
Especifique:

( ) NS

( ) NR

27-Havia degraus no local da queda?

( ) $\mathrm{Sim}$

( ) Não

( ) NS

( ) NR

28-Como estava a iluminação no local da queda?

( ) Claro

( ) Escuro

( ) NS

( ) NR

29-Qual o horário da queda?

( ) Manhã

( ) Hora do almoço

( ) Á tarde

( ) no fim da tarde

( ) À noite

30-Havia tapetes no local da queda?

( ) $\mathrm{Sim}$

( ) Não

( ) NS

( ) NR 


\section{APÊNDICE C}

\section{Mini Mental ( BRUCKI et.al., 2003)}

Agora vou lhe fazer algumas perguntas que exige atenção e um pouco de memória. Por favor tente se concentrar para responde-las.

Pontuação: ( 1) Certo e (0) errado

Orientação Data

Que dia é hoje ?( registre os itens omitidos)

dia ( ), mês ( ), ano ( ), dia da semana ( ), hora aproximada ( ）

Orientação Local

Onde você está ? pergunte os itens omitidos) país ( ), estado ( ), cidade ( ), local ( ), andar ( )

Registro de objetos

Nomeie clara e lentamente 3 objetos e peça ao paciente para repetir) carro ( ), vaso ( ), tijolo ( )

Sete Seriado (diminuir 7 de 100 sucessivamente ou soletrar mundo ao contrário)

$$
\text { 93( ), 86( ), 79( ), 72( ),65( ) ou O( ), D( ), N( ), U( ), M( ) }
$$

\section{Recordar Objetos}

Relembrar os 3 objetos citados anteriormente)

carro ( ), vaso ( ), tijolo ( )

Denominação

Aponte para o relógio e pergunte "O que é isto ?". (Repita com um lápis) 
relógio ( ), lápis ( )

\section{Repetição}

Repetir a frase ( "nem aqui, nem ali, nem lá")

repetição correta na $1^{a}$ tentativa ( )

\section{Comando Verbal}

Pegue este papel com a mão direita, dobre-o ao meio e coloque-o no chão) pegar o papel com a mão correta ( ), dobrar ao meio ( ), coloca no chão ( )

\section{Comando Escrito}

Mostrar um pedaço de papel com a frase "Feche os olhos")

fechou os olhos ( )

Escrita:(Escrever uma frase)

Desenho

Copiar um desenho ( )

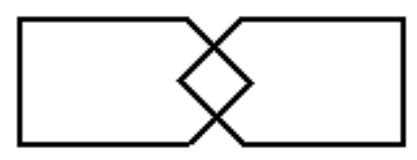

TOTAL (máximo = 30)

OBS: considerar pontuação Zero(0) nas questões que os idosos não consigam responder as questões, seja porque a questão exija que o idosos sejam alfabetizados e ele é analfabeto ou porque ele não soube responder por outro motivo. 


\section{APÊNDICE D \\ V. AVALIACÃO DO DESEMPENHO FÍSICO DE MMII E MMSS \\ V.1 Avaliação do desempenho físico de membros inferiores Shor Physical Perfornance Battery (SPPB) GURALNIK, J. M. (1994)}

\section{TESTE DE EQUILÍBRIO}

Assinale o quadrado, caso obtenha pontuação zero, assinale o motivo abaixo e passe para o teste seguinte.

58. $\underline{1}^{\circ}$ PosICÃ̃: Pés unidos em paralelos.

$$
1 . \begin{aligned}
& \left(10^{\prime \prime} \rightarrow 0\right. \text { ponto. Marque o tempo } \\
& \text { Assinale o motivo abaixo e siga para o próximo teste (teste de velocidade de marcha). } \\
& \text { () } \geq 10^{\prime \prime} \rightarrow 1 \text { ponto. Passe para a } 2^{\circ} \text { posição. }
\end{aligned}
$$

59. $2^{\circ}$ PosICÃo: Hálux encostado na borda medial do calcanhar.

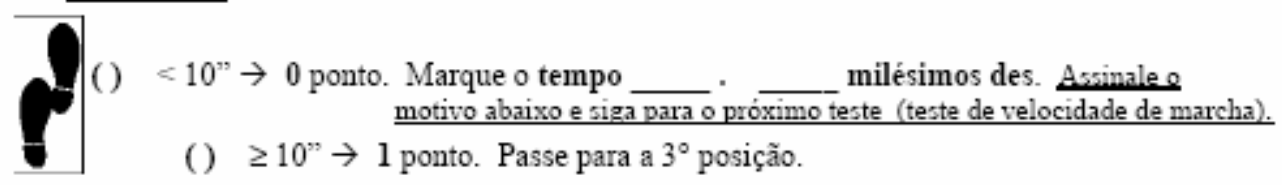

60. $3^{\circ}$ Posıc:Ão: Hálux encostado na borda posterior do calcanhar.

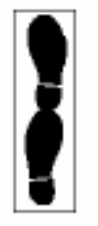

( ) $<3 n \rightarrow 0$ ponto. Marque o tempo milésimos des.

Assinale o motivo abaixo e siga para o próximo teste (teste de velocidade de marcha).

() $3 " \geq \mathrm{e} \leq 9 " .99 \rightarrow 1$ ponto

() $\geq 10^{\prime \prime} \rightarrow 2$ pontos

61. $\rightarrow$ SOMA TOTAL dos PoNTOS NAS 3 POSIC̣õES (PONTUAC̣Ão EQUILÍBRIO)

62. Assinale $\mathbf{x}$ no motivo abaixo, caso a pontuação tenha sido igual a zero:

( ) Tentou, mas não conseguiu;

( ) Participante não é capaz de ficar na posição sem auxilio;

( ) O avaliador sente-se insegurança para deixá-lo na posição;

( ) O participante sente-se inseguro para ficar na posição;

( ) O participante é incapaz de entender a explicação do teste;

( ) Outra questão especifica;

( ) O participante recusou.

Comentários 
Caminhar normalmente como se fosse atravessar a rua, repetir 2 vezes o teste. Pode ser utilizado meio auxiliar de marcha, menos cadeira de rodas. Se ele é incapaz de realizar, assinale o motivo e siga para o teste seguinte.

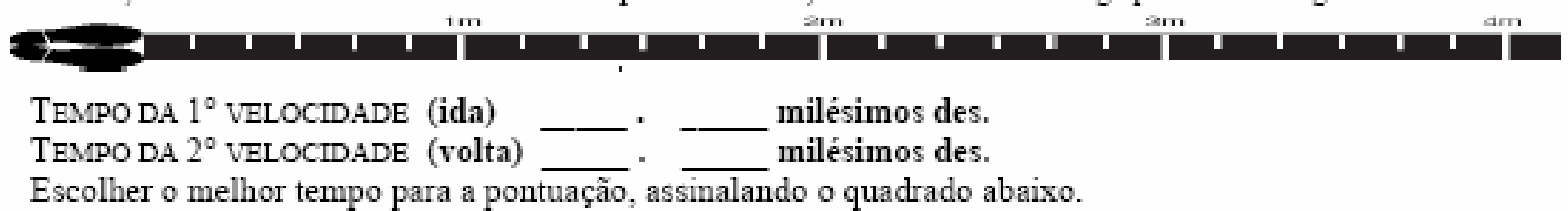

() $<4.82 " \rightarrow 4$ pontos

() $4.82 " \geq \mathrm{e} \leq 6.20$ " $\rightarrow 3$ pontos

() $6.21 \geq \mathrm{e} \leq 8.70^{\prime \prime} \rightarrow 2$ pontos

() $>8.70^{\prime \prime} \rightarrow 1$ ponto

() Incapaz $\rightarrow 0$ ponto.

64. ASSINALE X NO MOTIVO ABAIXO:

( ) Tentou, mas não conseguiu;

( ) O participante não pode caminhar sem auxilio ou ajuda;

( ) $O$ avaliador sentiu insegurança para realizar o teste;

( ) O participante sentiu-se inseguro para realizar o teste;

( ) O participante não entendeu as instruções do teste;

( ) Outro motivo especifico:

( ) O participante recusou.

65. QUAL A DIFICULDADE NESTE TESTE:

Comentários:

\section{TESTE DE FORÇA DE MEMBROS INFERIORES $\rightarrow$ PONTUACุÃo FORCุA}

Primeiro realizar um Pré-teste: levantar-se apenas 1 vez da cadeira:

- Caso NÃO consiga ou utilize as mãos, pare o teste, assinale o motivo abaixo e siga para a pontuação final SPPB

Caso SIM consiga, repita o teste 5 vezes consecutivas o mais rápido possivel, com os Membros superiores cruzados sobre peito e marque o tempo: milésimos des. Caso o participante use os braços ou não consiga completar as 5 repetições ou demore mais que 1 minuto para completar, finalize o teste e pontue zero e assinale o motivo abaixo.

Posição Posição

Inicial Final

() $>16 " .7 \rightarrow 1$ ponto

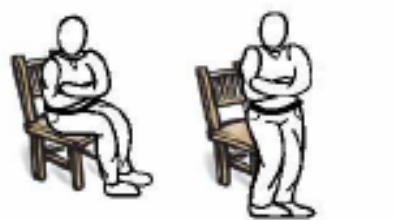

() $3^{\prime \prime} .70 \geq \mathrm{e} \leq 16^{\prime \prime} .69 \rightarrow 2$ pontos

() $11^{\prime \prime} .20 \geq \mathrm{e} \leq 13^{\prime \prime} .69 \rightarrow 3$ pontos

() $<11 " .19 \rightarrow 4$ pontos

() Incapaz ou tempo $\geq 60 " \rightarrow 0$ ponto.

\section{ASSINALE XNO MOTIVO ABALXO:}

( ) Tentou, mas não conseguiu;

( ) O participante não consegue levantar-se sem auxilio;

( ) $O$ avaliador não teve segurança para realizar o teste;

( ) O participante sentiu-se inseguro para realizar o teste;

( ) O participante não conseguiu entender as instruçôes do teste;

( ) Outro motivo específico:

( ) O participante se recusou.

Comentánios:

68. PONTUAÇÃO FINAL DO SPPB: $\rightarrow$ Soma Total das pontuações nos 3 Testes: 